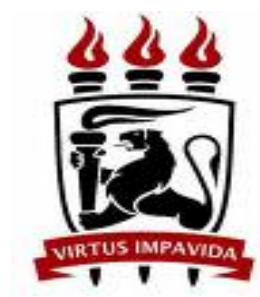

UNIVERSIDADE FEDERAL DE PERNAMBUCO

CENTRO DE FONOAUDIOLOGIA

DEPARTAMENTO DE FONOAUDIOLOGIA

PROGRAMA DE PÓS-GRADUAÇÃO EM SAÚDE DA COMUNICAÇÃO HUMANA

RAYANE FERREIRA DA SILVA

EFEITO DA IDADE E DA TAXA DE MODULAÇÃO

NO RECONHECIMENTO DA FALA INTERMITENTE

Recife

2019 
RAYANE FERREIRA DA SILVA

\section{EFEITO DA IDADE E DA TAXA DE MODULAÇÃO NO RECONHECIMENTO DA FALA INTERMITENTE}

Dissertação apresentada ao Programa de PósGraduação em Saúde da Comunicação Humana da Universidade Federal de Pernambuco, como requisito parcial para obtenção do título de Mestre.

Área de concentração: Audição e Linguagem: desenvolvimento, diagnóstico e intervenção fonoaudiológica.

Orientadora: Prof $^{\mathrm{a}}$. Dr ${ }^{\mathrm{a}}$. Denise Costa Menezes.

Recife 
Catalogação na fonte:

Bibliotecária: Elaine Freitas, CRB4:1790

S586e Silva, Rayane Ferreira da.

Efeito da idade e da taxa de modulação no reconhecimento da fala intermitente/ Rayane Ferreira da Silva. - 2019.

62 f.; il.

Orientadora: Denise Costa Menezes.

Dissertação (mestrado) - Universidade Federal de Pernambuco, Centro de Ciências da Saúde. Programa de pós-graduação em Saúde da Comunicação Humana. Recife, 2019.

Inclui referências, apêndice e anexos.

1. Audição. 2. Idoso. 3. Teste de discriminação de fala. 4. Percepção da fala I. Menezes, Denise Costa (orientadora). II. Título. 


\title{
EFEITO DA IDADE E DA TAXA DE MODULAÇÃO NO RECONHECIMENTO DA FALA INTERMITENTE
}

\begin{abstract}
Dissertação apresentada ao Programa de PósGraduação em Saúde da Comunicação Humana da Universidade Federal de Pernambuco, como requisito parcial para obtenção do título de Mestre.
\end{abstract}

Aprovada em: 16/04/2019.

\section{BANCA EXAMINADORA}

Prof $^{a}$. Dr ${ }^{\mathrm{a}}$. Denise Costa Menezes.

Universidade Federal de Pernambuco

Prof. Dra ${ }^{\mathbf{a}}$ Karina Paes Advíncula

Universidade Federal de Pernambuco

Prof $^{a}$. Dr ${ }^{\mathrm{a}}$. Silvana Maria Sobral Griz

Universidade Federal de Pernambuco

Prof. Dr ${ }^{\mathrm{a}}$. Liliane Pereira Desgualdo

Universidade Federal de São Paulo 
À minha mãe, por toda a dedicação, incentivo e amor para comigo. À minha avó, exemplo maior de fé, perseverança e coragem. 


\section{AGRADECIMENTOS}

A Deus, ser supremo, criador e regente de tudo o que existe. Agradeço pelo dom da vida, sabedoria e discernimento.

À Maria José, minha mãe, que não mediu esforços para que eu chegasse até esta etapa de minha vida. Pelo suporte constante, por se permitir sonhar comigo, e partilhar das realizações e conquistas alcançadas. A ti, meu eterno amor e gratidão.

À minha amada avó, Maria Balbino, por ter dedicado parte de seu tempo investindo em minha educação e por apresentar-me os preceitos religiosos e morais. Obrigada pelo imenso amor, pelos valores, apoio e incentivo nos momentos difíceis, de desânimo e cansaço.

Aos meus familiares, pelo suporte e encorajamento incondicional.

À minha orientadora Profa. Dra. Denise Costa Menezes, por compartilhar comigo toda sua competência e enriquecedoras ideias. Pela acolhida, confiança e ânimo no decorrer desta jornada. Tens todo o meu respeito, carinho e admiração.

Aos membros que compõe a banca avaliadora, Profa. Dra. Karina Paes Advíncula e Prof $^{a}$. Dr ${ }^{\mathrm{a}}$. Liliane Desgualdo Pereira, pelas tão importantes contribuições apresentadas a este trabalho.

Ao grupo de pesquisa em Audiologia, pela grande contribuição na construção de trabalhos produzidos. Admiro a parceria que há entre o grupo, a inteligência inenarrável dos integrantes, a paixão e o compromisso que têm para com a inovação da ciência.

Ao National Institute of Health, na pessoa de Dr. John H. Grose, da Universidade da Carolina do Norte, que concedeu os equipamentos para este e demais estudos.

Aos participantes desta pesquisa, pela disponibilidade e paciência, contribuindo de forma incomensurável. Sem vocês nada disso seria possível.

Aos meus amigos, que tanto torceram e vibraram com minhas conquistas. Por serem âncoras, pelas palavras de apoio, por tornarem mais leve a caminhada.

Aos colegas da turma do Mestrado, companheiros nessa jornada, que contribuíram durante todo o curso com discussões e apoio mútuo. Admiro a força de cada um de vocês.

À amiga Ysa Mcambira, que sempre esteve ao meu lado, compartilhando conhecimentos, me apoiando e acreditando juntamente comigo na concretização deste sonho. 
E a todos que, direta ou indiretamente, contribuíram para a realização deste trabalho, meus sinceros agradecimentos. 
"Foi o tempo que dedicastes à tua rosa que a fez tão importante" (SAINT-EXUPÉRY, 2005, p. 69). 


\section{RESUMO}

Idosos com limiares auditivos normais frequentemente relatam dificuldades em compreensão da fala em ambientes ruidosos. Acredita-se que essa dificuldade esteja relacionada a alterações no processamento auditivo temporal. O objetivo do presente estudo foi investigar o reconhecimento auditivo da fala intermitente em função de diferentes taxas de modulação e em função da idade. Participaram do estudo 20 adultos jovens (idade média de 21 anos), 20 adultos de meia idade (idade média de 48 anos) e 16 idosos (idade média de 65 anos), todos com limiares auditivos melhores que $25 \mathrm{~dB}$ NA até a frequência de $4000 \mathrm{~Hz}$. Os participantes foram submetidos à realização de testes de reconhecimento da fala intermitente, apresentada em três condições de modulação: 4 Hz, 10 Hz e 64 Hz. Como material linguístico, foram utilizadas as listas de sentenças da versão brasileira do Hearing in Noise Test (HINT). Foram determinados percentuais de reconhecimento para fala para cada condição de teste (4 $\mathrm{Hz}, 10 \mathrm{~Hz}$ e $64 \mathrm{~Hz}$ de modulação). Foi verificado um efeito da idade no reconhecimento da fala segmentada: indivíduos com mais idade apresentaram maior dificuldade em reconhecer a fala segmentada em tempo. Percebe-se ainda um efeito de taxa de modulação nos três grupos etários: quanto maior a taxa, melhor o desempenho.

Palavras-chave: Audição. Idoso. Teste de discriminação de fala. Percepção da fala. 


\begin{abstract}
Normal hearing older subjects often report difficulties in understanding speech in noisy environments. It is believed that this difficulty is related to changes in auditory temporal processing. The objective of this study was to investigate intermittent speech recognition as a function of different modulation rates and as a function of age. Participants were divided in three groups: 20 young listeners (mean age of 21 years old), 20 middle-aged adults (mean age of 65 years old) and 14 elderly (mean age of 67 years old), all with hearing thresholds better than $25 \mathrm{~dB}$ HL up to $4000 \mathrm{HZ}$. The participants were submitted to a speech recognition test, in which speech were amplitude modulated in three different rates (one for each testing condition): $4 \mathrm{~Hz}, 10 \mathrm{~Hz}$ and $64 \mathrm{~Hz}$. For this, Brazilian Portuguese sentences of the Hearing in Noise Test (HINT) were used. Correct percentages were determined for each test condition. It was observed an age effect on the segmented speech recognition: older individuals presented greater difficulty in recognizing segmented speech in time. A modulation rate effect on all groups was also observed: correct values increased as modulation rate increased.
\end{abstract}

Keywords: Hearing. Elderly. Speech discrimination tests. Speech perception. 


\section{SUMÁRIO}

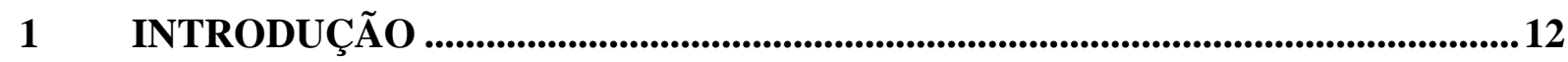

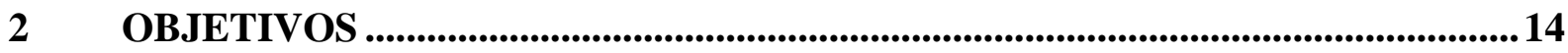

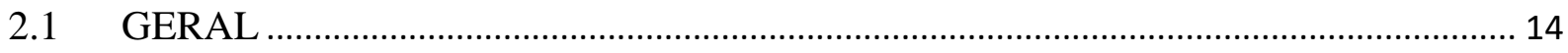

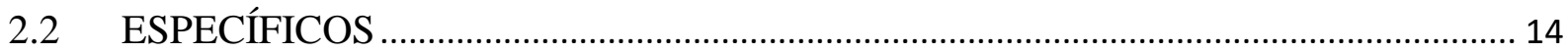

3 FUNDAMENTAÇÃO TEÓRICA........................................................................15

3.1 O PROCESSAMENTO AUDITIVO........................................................................ 15

3.2 PROCESSAMENTO AUDITIVO TEMPORAL …………………………………….... 16

3.3 RECONHECIMENTO AUDITIVO DA FALA …………………………………... 18

4 PROCEDIMENTO METODOLÓGICO...............................................................20

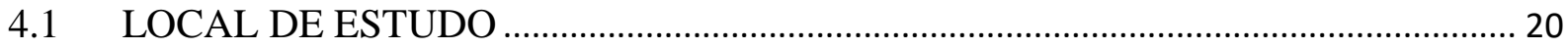

4.2 POPULAÇÃO DE ESTUDO..................................................................................... 20

4.3 PERÍODO DE REFERÊNCIA ................................................................................... 20

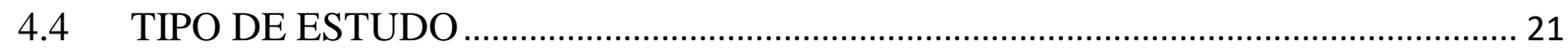

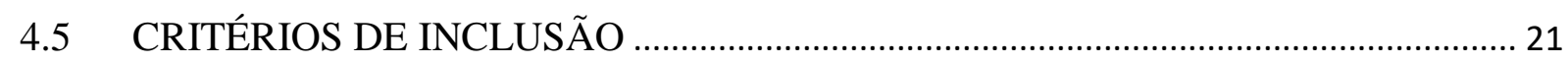

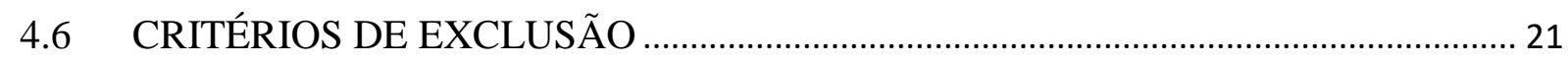

4.7 SELEÇÃO DA AMOSTRA ………………………………………………………….... 21

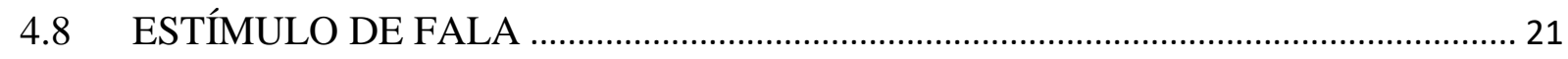

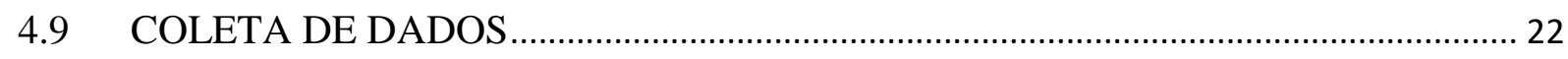

4.10 ANÁLISE DOS DADOS …………………………………………………... 23

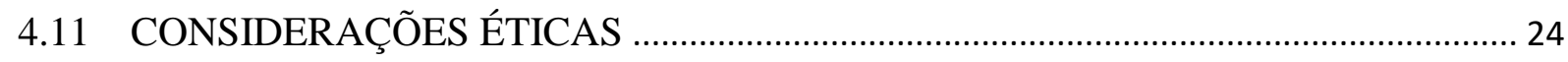

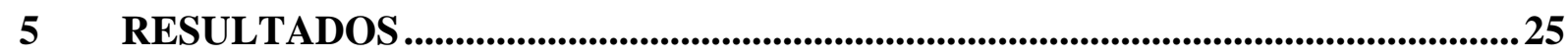

5.1 ARTIGO ORIGINAL - EFEITO DA IDADE E DA TAXA DE MODULAÇÃO NO RECONHECIMENTO DA FALA INTERMITENTE ………………………………….....2

REFERENCIAS ...........................................................................................45

APÊNDICE A - TERMO DE CONSENTIMENTO LIVRE E ESCLARECIDO.52 
ANEXO A - LISTAS DE SENTENÇAS HINT ADAPTADO PARA O PORTU -

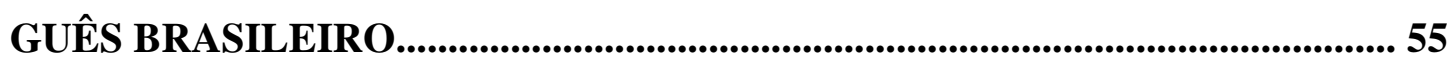

ANEXO B - PARECER CONSUBSTANCIADO DO CEP .59 


\section{INTRODUÇÃO}

Em muitas interações sociais permeadas por comunicação oral, a fala do interlocutor é apenas um dos sons contidos no ambiente. Outros sons, também presentes, podem mascarar, mesmo que parcialmente, o estímulo de fala que se deseja ouvir. Isso acontece quando o ruído ambiental coincide em tempo e/ou em espectro de frequência com a fala. Nessa situação, caracterizada por condição de escuta em baixa redundância, o ouvinte passa a perceber apenas os segmentos da fala que não coincidem, em características acústicas e temporais, com o ruído mascarante. O resultado é a percepção de uma fala intermitente (segmentada em intervalos de tempo) e/ou distorcida (segmentada em espectro de frequência). O reconhecimento adequado da fala em situações dessa natureza demanda que o ouvinte seja capaz de atribuir um significado a uma fala com inúmeras janelas de tempo, ou inúmeras frequências faltando. É dessa forma que, em situações de escuta da fala em presença concomitante de ruído, a mensagem do interlocutor será percebida e interpretada pelo ouvinte (CAHART; TILLMAN; GREETIS, 1969; CAPORALI; SILVA, 2004).

A dificuldade em reconhecer sons da fala em ambientes ruidosos aumenta com o avanço da idade. A perda auditiva sensorial, comum na população idosa, é referida como uma das causas de dificuldade do idoso em reconhecer sons da fala (HUMES; CHRISTOPHERSON, 1991; CAPORALI; SILVA, 2004). No entanto, estudos apontam que independentemente de qualquer déficit na sensibilidade auditiva, idosos com audição dentro dos padrões de normalidade, quando comparados a jovens ouvintes, apresentam maior dificuldade no reconhecimento da fala em ambientes ruidosos (VERSFELD; DRESCHLER, 2002; CAPORALI; SILVA, 2004; GORDON-SALANT, 2006; DESLOGE et al., 2010).

Sabe-se que o mascaramento temporal está relacionado à dificuldade em reconhecer a fala em ambientes ruidosos (GROSE; MAMO, 2010; HALL et al., 2012). O mascaramento temporal caracteriza-se pela mudança de limiar de um som na presença de outro estímulo subsequente. Isto ocorre quando um estímulo é apresentado com duração e intensidade suficientes para reduzir a sensibilidade de um outro estímulo (SHINN, 2003).

Estudos mostram que o efeito do mascaramento temporal é maior em idosos com limiares auditivos normais, quando comparados à jovens, também de audição normal (GEORGE et al.,2007; GIFFORD; BACON; WILLIAMS, 2007; GROSE; MAMO; HALL, 2009; WILSON et al., 2010). Percebe-se portanto, que o mascaramento temporal está relacionada à maior dificuldade do idoso em reconhecer a fala em ambientes ruidosos (GROSE; 
PORTER; BUSS, 2016). No entanto, uma questão ainda vigente é se algum outro fator, além do efeito do mascaramento temporal, pode estar relacionado à essa dificuldade.

Uma possibilidade seria o declínio natural da habilidade de reconhecer a fala em baixa redundância. Mais especificamente, nesse caso, a fala intermitente (segmentada em tempo), semelhante à fala percebida por ouvintes em ambientes ruidosos. Surge, então, a pergunta condutora do presente estudo: será que a habilidade de reconhecer a fala intermitente naturalmente declina em função da idade?

A hipótese é que a habilidade de reconhecer a fala intermitente decline com o avanço da idade. Talvez, uma queda no desempenho dessa habilidade possa, inclusive, ser identificada em adultos de meia idade, que ainda não atingiram a senescência. Essa hipótese será testada nesse estudo através da comparação do desempenho de três grupos etários (jovens, adultos de meia idade e idosos) em testes de reconhecimento da fala intermitente (segmentada em tempo). A comprovação dessa hipótese irá corroborar com a linha de raciocínio que segue em direção à necessidade de ações preventivas e de intervenção voltadas para uma saudável sociabilidade das pessoas.

O estudo justifica-se por ser a audição peça fundamental para comunicação das pessoas em ambientes de interação social, e principalmente, pelo aumento das dificuldades auditivas e desafios relacionados à sociabilização dos idosos. Esses fatores fizeram com que nos últimos anos, o interesse de estudiosos sobre o assunto aumentasse (GROSE; MAMO, 2010; 2012; HALL et al., 2012; CALAIS et al., 2016). 


\section{OBJETIVOS}

\subsection{GERAL}

Investigar o reconhecimento auditivo da fala intermitente em função de diferentes taxas de modulação e em função da idade.

\subsection{ESPECÍFICOS}

a) Determinar índices percentuais de reconhecimento auditivo da fala intermitente em diferentes taxas de modulação $(4 \mathrm{~Hz}, 10 \mathrm{~Hz}$ e $64 \mathrm{~Hz})$ em jovens, adultos de meia idade e idosos com audição periférica normal;

b) Comparar índices de acerto entre os diferentes grupos etários em cada condição de teste (taxa de modulação) estudada (investigação do efeito de idade).

c) Comparar índices de acerto entre as diferentes taxas de modulação em cada grupo estudado (investigação do efeito de taxa de modulação). 


\section{FUNDAMENTAÇÃO TEÓRICA}

Para uma boa reprodução do que escutamos é preciso ouvir bem, e isso envolve não somente uma boa detecção auditiva, mas também um processamento sensorial eficiente das informações auditivas pelo sistema auditivo central (ISHII; ARASHIRO; PEREIRA, 2006).

A audição é uma função cortical que, para ocorrer adequadamente, requer a integridade do sistema auditivo periférico, do sistema auditivo central e de processos do sistema nervoso central (SENS; ALMEIDA, 2007). O sistema auditivo periférico recebe estímulos auditivos do meio ambiente e os conduz ao sistema auditivo central, que junto com o cérebro, analisam as representações internas desses estímulos acústicos (IZQUIERDO; OLIVER; MALMIERCA, 2009).

Por meio do processamento auditivo, que é a capacidade do sistema nervoso codificar a mensagem sonora recebida do ambiente, o indivíduo recebe as informações acústicas utilizando habilidades auditivas que são essenciais para ele apreender o que ouve. A habilidade mais importante da função auditiva humana é a capacidade para entender a fala (CAPORALI; SILVA, 2004), e essa habilidade ocorre devido aos mecanismos englobados pelo processamento auditivo.

\subsection{PROCESSAMENTO AUDITIVO}

Segundo a American Speech-Language-Hearing Association (ASHA, 2005), o processamento auditivo (PA) é a eficácia com a qual o sistema nervoso central utiliza a informação auditiva. É responsável pelos seguintes fenômenos comportamentais: localização e lateralização sonora, discriminação auditiva, reconhecimento de padrões auditivos, aspectos temporais da audição (resolução temporal, mascaramento temporal, integração temporal e ordenação temporal), desempenho auditivo na presença de sinais acústicos competitivos e desempenho auditivo para sinais acústicos degradados.

O desenvolvimento adequado do processamento auditivo depende de fatores como maturação neurobiológica, habilidades cognitivas (atenção, memória e linguagem), integridade da audição periférica e estímulos ambientais (TERTO; LEMOS, 2011; LUZ; COSTAFERREIRA, 2011). O comprometimento de um ou mais desses fatores pode acometer o processamento fisiológico dos sons e levar à desordem das habilidades auditivas (LUCION; OLIVEIRA, 2010). 
Segundo Kraus e Nicol (2003), no transtorno do processamento auditivo a percepção auditiva da fala (que é um sinal acústico complexo) exige do sistema auditivo a percepção de mudanças rápidas no espectro e a recepção de muitos estímulos em curto espaço de tempo. Além disso, em muitas situações, a relação fala/ruído não é favorável.

Para alguns autores (SHINN, 2003; SHIBATA et al., 2004; SAMELLI; SCHOCHAT, 2008), a base do processamento auditivo são as habilidades do processamento auditivo temporal, especificamente no que diz respeito à percepção de fala, pois as características da informação auditiva são, de alguma forma, influenciadas pelo tempo.

\subsection{PROCESSAMENTO AUDITIVO TEMPORAL}

O processamento auditivo temporal pode ser definido como a percepção do som ou da alteração do som dentro de um período restrito e definido de tempo, ou seja, refere-se à habilidade de perceber ou diferenciar estímulos acústicos que são apresentados numa rápida sucessão. (SHINN, 2003; SMITH; TRAINOR; SHORE, 2006; SAMELLI; SCHOCHAT, 2008). Pode ser dividido em quatro categorias, sendo todas importantes para as habilidades de processamento auditivo. São elas: Ordenação ou seqüencialização temporal; Integração ou somação temporal; Mascaramento temporal; Resolução, discriminação ou acuidade temporal. (SHINN, 2003; MUNIZ et al., 2007; BARAN; MUSIEK apud MUSIEK; RINTELMANN, 2001).

A habilidade de ordenação temporal (sequencialização) refere-se ao processamento de vários estímulos auditivos na sequência em que eles ocorrem no tempo. Contribui, dessa forma, para que o indivíduo seja capaz de distinguir a ordem correta em que os sons são sucedidos (EGGERMONT, 2000; BELLIS, 2003). A resolução temporal, pode ser definida como a capacidade de identificação de intervalos de tempo entre estímulos sonoros, ou até mesmo a detecção do menor tempo em que uma pessoa possa discriminar dois sinais audíveis (EGGERMONT, 2000; SHINN, 2007). A Integração temporal ou somação temporal consiste na habilidade que o sistema auditivo possui de acumular informação durante algum tempo para favorecer a detecção ou discriminação de estímulos sonoros, ou seja, refere-se à capacidade de integrar características do estímulo ao longo do tempo (MOORE, 2003; RAWOOL, 2006; PLACK; SKEELS, 2007; RECANZONE et al., 2007). A integração temporal é a área de estudo mais antiga dentre os fenômenos temporais, no entanto, é a menos compreendida (NEVES; FEITOSA, 2003).

Mascaramento temporal é entendido como sendo um fenômeno onde um estímulo acústico tem seu limiar alterado perante a presença se outro estímulo subsequente. Isto ocorre 
quando um estímulo é apresentado com duração e intensidade suficientes para reduzir a sensibilidade de um outro estímulo (SHINN, 2003). O mascaramento temporal pode ser simultâneo (quando o ruído mascarante ocorre simultaneamente ao som mascarado), ou pode ter seu efeito prolongado ou antecipado (no tempo). Esse efeito de permanência do mascaramento é denominado na língua inglesa de foward masking e acontece quando o som alvo ocorre após o término do som mascarante, mas ainda sofre seu efeito. Já no efeito de antecipação do mascaramento (backward masking), o som alvo ocorre antes da presença do som mascarante, e também sofre seu efeito mascarante (DIRKS; BOWER, 1970; SHINN, 2003; FILIPPINI, R; SCHOCHAT, E., 2014).

Segundo Miller e Licklider (1950), a fala, quando em presença de ruído mascarante, é geralmente melhor reconhecida quando há modulação de amplitude ou de frequência desse ruído. Este fenômeno é conhecido na língua inglesa como masking release, e foi traduzido para o português como 'benefício do mascaramento modulado' (BMM) por Advíncula e colaboradores (2013).

Estudos relacionam as dificuldades de reconhecimento de fala em idosos à perda da capacidade de realizar o processamento temporal de sons (FRISINA; FRISINA, 1997; PARRA et al., 2004). Nessa população, além do declínio na habilidade de detectar sons (identificado em limiares audiométricos e caracterizado como perda auditiva sensorioneural), também pode-se observar, a presença de alterações nas funções cognitivas que, no idoso, é caracterizada por lentidão (BESS; HEDLEY-WILLIANS; LICHTESTEIN, 2001; PINHEIRO; PEREIRA, 2004).

Além da perda auditiva sensorioneural, a presbiacusia (perda auditiva relacionada à idade) é acompanhada por um declínio da função auditiva central que se manifesta através do aumento da dificuldade nas habilidades como reconhecimento da fala, fusão auditiva, figurafundo, atenção auditiva, julgamento auditivo, e uma diminuição na velocidade de fechamento e síntese auditiva (HULL, 1999).

Bertoli, Smurzynski e Probst, (2002) e Snell e Frisina (2000) demonstraram que a idade é um fator significativo no aumento do limiar de detecção de gap (intervalo de silêncio durante a apresentação de mais de um estímulo) em pacientes idosos, quando comparados com uma população adulta mais jovem.

Inúmeros estudos dizem que um dos maiores obstáculos enfrentados pelos idosos na comunicação é o reconhecimento de fala no ruído (PINHEIRO; PEREIRA, 2004; WONG et al., 2010; GORDON-SALANT; FITZGIBBONS; YENI- KOMSHIAN, 2011; GROSE; PORTER; BUSS, 2016; CALAIS et al., 2016). 
Compreender a fala em ambientes ruidosos é um desafio para qualquer ouvinte. Esta dificuldade é atribuída, em parte, aos efeitos negativos do ruído na sincronia neural, resultando em uma representação degradada da fala em níveis corticais e subcorticais (ANDERSON et al., 2010). Esta tarefa requer um conjunto complexo de habilidades cognitivas e perceptuais, incluindo a memória de trabalho auditiva, detecção e processamento de aspectos espectrais e temporais, além das habilidades auditivas de figura-fundo, fechamento auditivo e atenção seletiva (BECKER et al., 2011).

Existe uma relação forte entre o processamento auditivo temporal e o reconhecimento da fala. Especificamente, esse estudo visa investigar se existe um efeito da idade na habilidade de reconhecer a fala em baixa redundância (fala intermitente). O item a seguir irá explorar o assunto.

\subsection{RECONHECIMENTO AUDITIVO DA FALA}

Entender como o reconhecimento da fala intermitente e filtrada se dá em função da idade é importante (CAHART; TILLMAN; GREETIS, 1969; CAPORALI; SILVA, 2004). Para tal, muitos estudos investigam tal o reconhecimento da fala simulando situações ruidosas (CAPORALI; SILVA, 2004; CALAIS; RUSSO, BORGES, 2008; BECKER et al., 2011; JACOB et al., 2011; BERNSTEIN et al., 2012; ADVÍNCULA et al., 2013; SBOMPATO et al., 2015; BUZO; LOPES, 2017) porém, acredita-se que a investigação do reconhecimento de uma fala acusticamente modificada (para que se torne semelhante à fala percebida nas situações citadas), sem a presença do ruído, seja de igual importância na compreensão sobre o funcionamento da audição.

Uma forma de investigar o reconhecimento da fala em situações de baixa redundância e sem a presença de um ruído mascarador é usando a fala intermitente ou interrompida periodicamente com intervalos de silêncio (NELSON; JIN, 2004). Mesmo que não haja a presença do ruído, em situações como esta, é necessário que o ouvinte utilize mecanismos de cima para baixo para integrar os múltiplos fragmentos audíveis da fala original, mecanismos esses que provavelmente estão envolvidos no paradigma de mascaramento e no contexto real do mundo ruidoso (BHARGAVA; GAUDRAIN; BASKENT, 2016).

Enquanto que na fala interrompida a fala tem suas partes removidas e substituídas por silêncio, na fala com ruído há a presença de ruído competitivo, podendo mascarar a fala alvo. Porém, mesmo utilizando condições diferentes de estímulos, estudos já mostraram ter uma forte associação entre as duas abordagens (percepção da fala interrompida e percepção da fala no ruído). 
Cervera e Gonzalez-Albernaz (2011) afirmam que a investigação da percepção da fala tornou-se assunto bastante discutido na literatura, tornando-se fundamental a necessidade da utilização de testes que simulem situações reais de escuta para avaliar as dificuldades enfrentadas pelos sujeitos.

O material linguístico utilizado em estudos para esse fim geralmente é composto por palavras ou sentenças. Bronkhorst e Plomp (1990) alegam que o uso de sentenças é mais adequado, pois representam melhor as situações de comunicação diária.

$\mathrm{Na}$ habilidade para ouvir a fala, o indivíduo pode contar com auxílios intrínsecos e extrínsecos. Os intrínsecos são as múltiplas vias e tratos auditivos disponíveis no sistema nervoso auditivo central, enquanto os extrínsecos são as numerosas pistas dentro da própria fala. A língua dispõe de várias pistas para o ouvinte entender a mensagem: acústicas, sintáticas, semânticas, morfológicas e lexicais. Essas pistas nem sempre são necessárias a todo momento, porém, quando a mensagem está sendo dita em local ruidoso, essas redundâncias passam a ser de grande importância para a inteligibilidade da fala (SCHOCHAT, 1996).

O capitulo abaixo descreve o material linguístico que foi utilizado nesse estudo, assim como os procedimentos de coleta e análise dos dados. 


\section{PROCEDIMENTO METODOLÓGICO}

\subsection{LOCAL DE ESTUDO}

A pesquisa foi realizada no Laboratório de Audiologia do Departamento de Fonoaudiologia da Universidade Federal de Pernambuco.

\subsection{POPULAÇÃO DE ESTUDO}

A amostra foi composta por 56 participantes e dividida em três grupos: Grupo 01: composto por vinte jovens com idade entre 18 - 25 anos (idade média de 21 anos), ambos os gêneros (sendo 12 do gênero feminino); Grupo 02: composto por vinte adultos de meia idade com idade entre 45 -55 anos (idade média de 48 anos), ambos os gêneros (sendo 16 do gênero feminino); Grupo 03: composto por 16 idosos com idade entre 60 e 78 anos (idade média de 65 anos), ambos os gêneros (sendo 14 do gênero feminino). Todos os participantes apresentaram limiares audiométricos até $25 \mathrm{~dB}$ NA, nas frequências de 250 à $4000 \mathrm{~Hz}$, em pelo menos uma orelha (Figura 1).

Figura 1 - Representação gráfica das médias dos limiares audiométricos das orelhas testada para os três grupos etários.

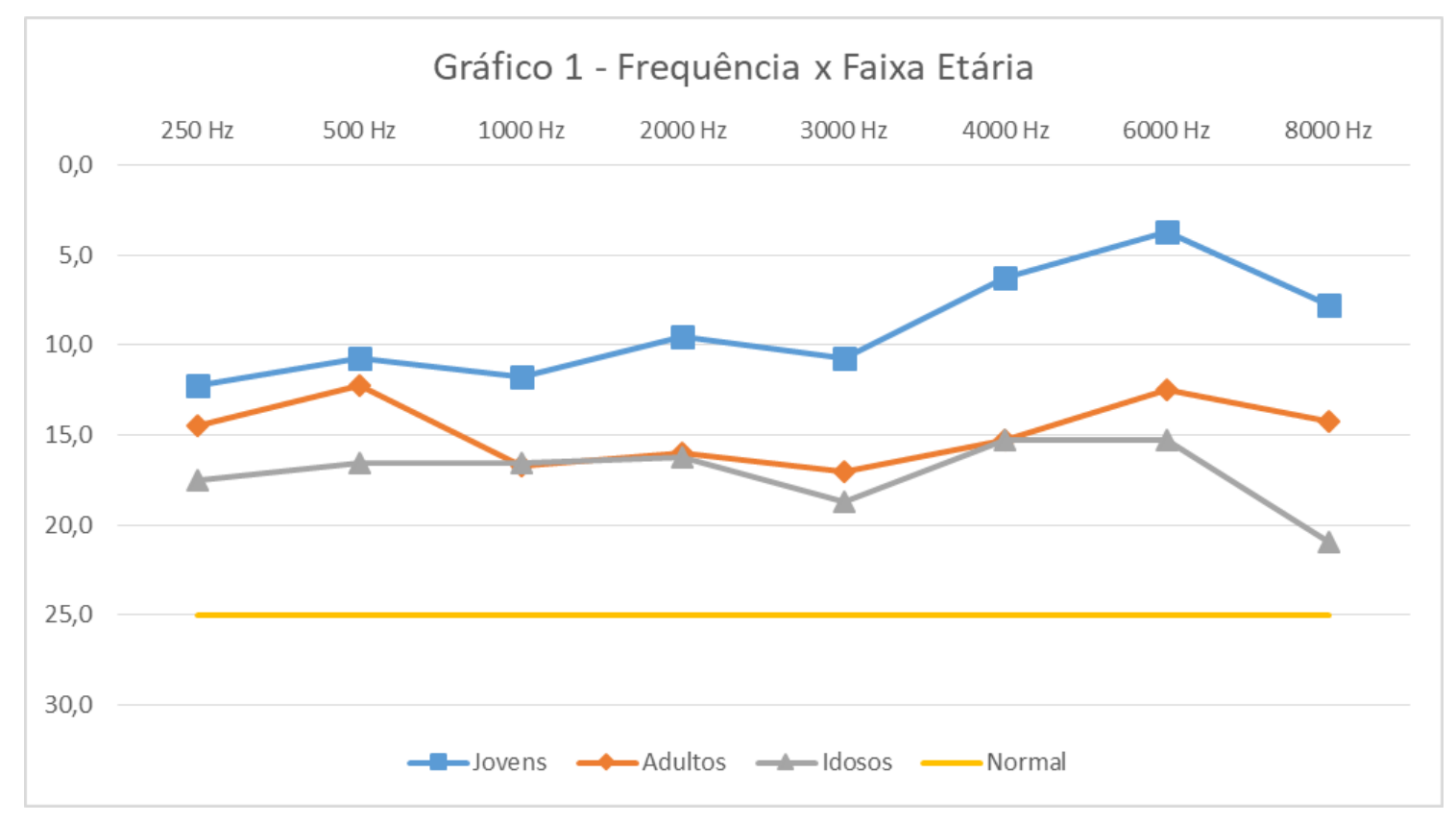

\subsection{PERÍODO DE REFERÊNCIA}

A coleta de dados foi realizada entre o período de Maio a Outubro de 2018. 


\subsection{TIPO DE ESTUDO}

Trata-se de um estudo observacional, analítico e transversal.

\subsection{CRITÉRIOS DE INCLUSÃO}

Como critério de inclusão no estudo, todos os indivíduos apresentaram limiares audiométricos até $25 \mathrm{~dB}$ NA, nas frequências de 250 à $4000 \mathrm{~Hz}$, em pelo menos uma orelha.

\subsection{CRITÉRIOS DE EXCLUSÃO}

Foram excluídos do estudo indivíduos que apresentaram diagnóstico de qualquer alteração no sistema auditivo, bem como, diagnóstico ou queixa de qualquer alteração neurológica ou psiquiátrica que pudesse interferir em qualquer grau na comunicação oral.

\subsection{SELEÇÃO DA AMOSTRA}

A amostra foi recrutada por conveniência. Os indivíduos que se enquadraram nas faixas etárias determinadas foram convidados a participar do estudo e, foram apresentados a todos os objetivos e procedimentos da pesquisa, incluindo explicação dos riscos e benefícios de sua participação. Após aceitarem participar da pesquisa, os participantes assinaram um Termo de Consentimento Livre e Esclarecido (TCLE) (APÊNDICE A) e, em data agendada, foram submetidos a audiometria tonal, que serviu como instrumento de inclusão, como descrito anteriormente.

\subsection{ESTÍMULO DE FALA}

As sentenças utilizadas no estudo fazem parte da versão brasileira do Hearing in Noise Test (HINT) (BEVILACQUA, 2008). Essa versão do HINT é composta por sentenças em Português Brasileiro de uso cotidiano. São doze listas com vinte sentenças cada, todas foneticamente balanceadas (ANEXO A) (BEVILACQUA, 2008). Adotou-se a regra de nunca repetir sentença para o mesmo participante, eliminando a chance de aprendizado.

As sentenças foram acusticamente modificadas através do processador de fala da marca Tucker Davis Technology, modelo RZ6 e do programa MATLAB ${ }^{\mathrm{TM}}$ (Matrix Laboratory). A segmentação temporal foi realizada através da modulação da amplitude do sinal acústico, realizada por um modulador de onda quadrática (square-wave modulator). As sentenças foram 
moduladas em 100\% (limitação total de amplitude), resultando em um som de fala interrompida, ou intermitente.

A fala intermitente foi apresentada em três condições (taxas) de modulação: $4 \mathrm{~Hz}, 10$ Hz e 64 Hz. Na condição de modulação em 4 Hz, a cada segundo de sentença apresentada houve quatro períodos nos quais a amplitude foi diminuída em 100\% (ciclo de modulação). Cada um dos ciclos de modulação durou $250 \mathrm{~ms}$, e por ter sido modulado em uma onda quadrática, metade desse tempo (12 5ms) foi caraterizado com ausência de informação acústica. Portanto, para cada segundo de fala, apenas metade desse tempo (500 ms) conteve a informação verbal da sentença. A Figura 2 ilustra a segmentação em 4 Hz: os blocos azuis representam o período de tempo com presença de informação verbal, e os espaços vazios representam os períodos de tempo sem informação acústica.

Figura 2 - Ilustração da fala segmentada em $4 \mathrm{~Hz}$.

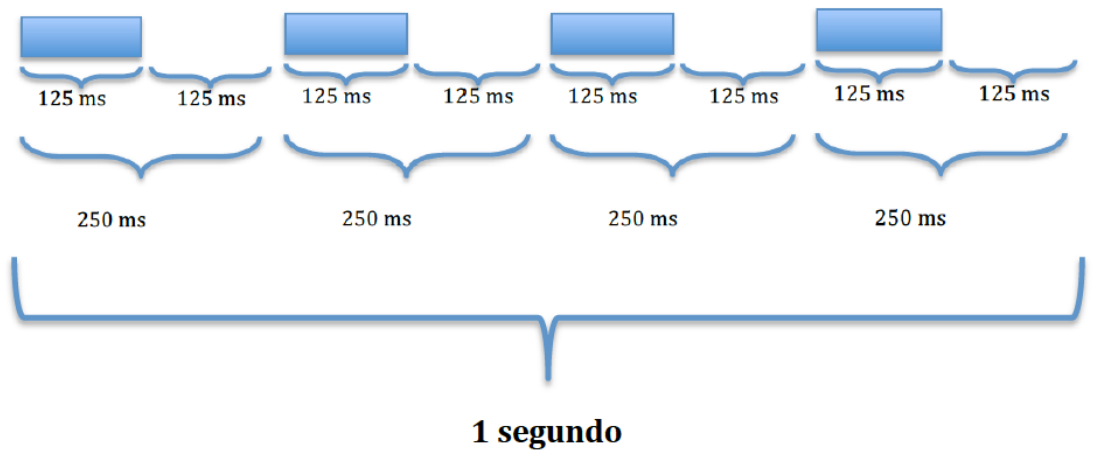

Nas demais taxas de modulação, seguiu-se a mesma programação. Na modulação de 10 $\mathrm{Hz}$, houve dez períodos de baixa de amplitude (ausência de informação acústica) e cada um durou 50 ms. Em $64 \mathrm{~Hz}$, os sessenta e quatro períodos de ausência de informação duraram 8 milissegundos cada um. Percebe-se que o tempo total de ausência de informação é o mesmo nas três condições de teste (500 ms para cada segundo), no entanto, o que difere é a distribuição entre os períodos com e sem ausência de som.

\subsection{COLETA DE DADOS}

Os participantes que atenderam aos critérios de inclusão foram convidados a prosseguir e realizar os testes com a fala intermitente. Para a realização do teste de fala, o participante foi posicionado sentado confortavelmente numa poltrona reclinável dentro de uma cabina acústica 
( 2 m x 2 m) com iluminação adequada e recebeu, através de fone auditivo Sennheiser HD580, o estímulo de fala. Foi escolhida para o teste a orelha de melhor audição ou a orelha direita, quando ambas apresentarem acuidade auditiva semelhante. Os participantes foram instruídos a repetir as sentenças como escutaram, mesmo que nem todas as palavras fossem inteligíveis.

O pesquisador, localizado fora da cabina acústica, controlou o material de fala utilizado no teste, monitorou e registrou os erros cometidos pelos participantes. À medida em que cada sentença era apresentada, o texto aparecia na tela do computador do pesquisador, com todas as palavras em destaque num retângulo sombreado sensível à marcação. $\mathrm{O}$ pesquisador utilizou o mouse do computador para marcar as palavras omitidas ou repetidas incorretamente.

Em cada condição testada foram utilizadas 25 sentenças, apresentadas de forma randomizada entre os participantes. A randomização na apresentação das sentenças foi realizada para eliminar um possível efeito do material linguístico nos resultados. Exemplificando: o participante 1 foi testado na condição de $4 \mathrm{~Hz}$ com 25 sentenças, iniciando na lista 1, sentença 1 até a lista 2 sentença 5 . O próximo participante começou na lista 2 , sentença 6 , até a lista 3 , sentença 10, e assim por diante. O mesmo acontece em todas as condições de teste.

Através do programa MATLAB, foram determinados índices de acertos para cada condição testada. O cálculo foi realizado de acordo com a quantidade de palavras utilizadas nas vinte e cinco sentenças testadas (o total de palavras variou entre as condições, já que as sentenças eram diversificadas quanto a sua quantidade de caracteres).

Para cada participante, e em cada condição de teste (4, 10 e $64 \mathrm{~Hz})$, foram determinados três índices de acerto no reconhecimento das sentenças. Posteriormente, foi realizada a média aritmética dos três resultados de cada condição de modulação, sendo essa média o resultado considerado para análise estatística.

Durante o teste, o pesquisador não forneceu qualquer pista ao participante em relação a seu desempenho. Intervalos para descanso foram realizados sempre que necessário.

\subsection{ANÁLISE DOS DADOS}

A análise dos dados foi realizada pelos softwares STATA/SE 12.0 e Excel 2010. Todos os testes foram aplicados com $95 \%$ de confiança.

Para verificar a normalidade dos dados, utilizou-se o teste de Kolmogorov-Smirnov para variáveis quantitativas, e como resultados, obtivemos: para $4 \mathrm{~Hz}$ as variáveis estão normalmente distribuídas. Para 10 Hz e 64 Hz apresentam distribuição não normal. 
Portanto, para investigação do efeito da taxa de modulação foi realizada a análise de variância (ANOVA) com Post Hoc de Tukey (Distribuição Normal) e Kruskal Wallis com comparação múltipla de Dunn's (para a Distribuição não Normal).

Para a investigação do efeito da idade, utilizou-se um método para medidas repetidas: o modelo de regressão linear misto, que leva em consideração a possível correlação entre os valores da variável resposta que constituem medidas repetidas.

\subsection{CONSIDERAÇÕES ÉTICAS}

O projeto faz parte de um projeto guarda-chuva, aprovado pelo Comitê de Ética e Pesquisa (CEP) envolvendo Seres Humanos, do Centro de Ciências da Saúde da Universidade Federal de Pernambuco (UFPE), sob CAAE: 81081417.1.0000.5208 e parecer de número 2.532.384 (ANEXO B).

Todos os indivíduos que concordaram em participar da pesquisa, foram solicitados a ler e assinar um Termo de Consentimento Livre e Esclarecido (TCLE), que os deixaram cientes do objetivo do estudo, seus riscos e benefícios, do sigilo quanto a sua identidade, e da utilização dos dados colhidos para os fins de pesquisa, bem como a possibilidade de desligar-se da pesquisa no momento em que desejassem, sem que isso os prejudicassem de alguma forma.

A pesquisa apresentou riscos mínimos que podem ser traduzidos na representação de constrangimento, e possível desconforto e/ou cansaço pelo tempo que foi gasto. Caso isto acontecesse, o voluntário foi instruído a avisar ao entrevistador, onde o mesmo imediatamente interromperia o procedimento.

Quanto aos benefícios, os participantes receberam cópia do exame de audiometria tonal, assim como orientações sobre sua audição. Quando identificada alguma alteração auditiva, os participantes foram submetidos a avaliação audiológica mais detalhada e encaminhados para avaliação otorrinolaringológica. 


\section{RESULTADOS}

Os resultados da pesquisa serão exposto através do artigo científico original abaixo.

\subsection{ARTIGO ORIGINAL}

Efeito da idade e da taxa de modulação no reconhecimento da fala intermitente.

Rate modulation and aging effect on intermittent speech recognition.

\section{RESUMO}

O objetivo do presente estudo foi investigar o reconhecimento auditivo da fala intermitente em função de diferentes taxas de modulação e em função da idade. Participaram do estudo 20 adultos jovens (idade média de 21 anos), 20 adultos de meia idade (idade média de 48 anos) e 16 idosos (idade média de 65 anos), todos com limiares auditivos melhores que 25 dB NA até a frequência de $4000 \mathrm{~Hz}$. Os participantes foram submetidos à realização de testes de reconhecimento da fala intermitente (segmentada em tempo), apresentada em três condições de modulação: $4 \mathrm{~Hz}, 10 \mathrm{~Hz}$ e $64 \mathrm{~Hz}$. Como material linguístico, foram utilizadas as listas de sentenças da versão brasileira do Hearing in Noise Test (HINT). Foram determinados percentuais de reconhecimento para fala para cada condição de teste $(4 \mathrm{~Hz}, 10 \mathrm{~Hz}$ e $64 \mathrm{~Hz}$ de modulação). Foi verificado um efeito da idade no reconhecimento da fala segmentada: indivíduos com mais idade apresentaram maior dificuldade em reconhecer a fala segmentada em tempo. Percebe-se ainda um efeito de taxa de modulação nos três grupos etários: quanto maior a taxa, melhor o desempenho.

Descritores: Audição; Idoso; Teste de discriminação de fala; Percepção da fala. 


\begin{abstract}
Normal hearing older subjects often report difficulties in understanding speech in noisy environments. It is believed that this difficulty is related to changes in auditory temporal processing. The objective of this study was to investigate intermittent speech recognition as a function of different modulation rates and as a function of age. Participants were divided in three groups: 20 young listeners (mean age of 21 years old), 20 middle-aged adults (mean age of 65 years old) and 14 elderly (mean age of 67 years old), all with hearing thresholds better than $25 \mathrm{~dB}$ HL up to $4000 \mathrm{HZ}$. The participants were submitted to a speech recognition test, in which speech were amplitude modulated in three different rates (one for each testing condition): $4 \mathrm{~Hz}, 10 \mathrm{~Hz}$ and $64 \mathrm{~Hz}$. For this, Brazilian Portuguese sentences of the Hearing in Noise Test (HINT) were used. Correct percentages were determined for each test condition. It was observed an age effect on the segmented speech recognition: older individuals presented greater difficulty in recognizing segmented speech in time. A modulation rate effect on all groups was also observed: correct values increased as modulation rate increased.
\end{abstract}

Keywords: Hearing; Elderly; Speech discrimination tests; Speech perception.

\title{
INTRODUÇÃO
}

Em muitas interações sociais permeadas por comunicação oral, a fala do interlocutor é apenas um dos sons contidos no ambiente. Outros sons, também presentes, podem mascarar, mesmo que parcialmente, o estímulo de fala que se deseja ouvir. Isso acontece quando o ruído ambiental coincide em tempo e/ou em espectro de frequência com a fala. Nessa situação, caracterizada por condição de escuta em baixa redundância, o ouvinte passa a perceber apenas os segmentos da fala que não coincidem, em características acústicas e temporais, com o ruído mascarante. $\mathrm{O}$ resultado é a percepção de uma fala intermitente (segmentada em intervalos de 
tempo) e/ou distorcida (segmentada em espectro de frequência). O reconhecimento adequado da fala em situações dessa natureza demanda que o ouvinte seja capaz de atribuir um significado a uma fala com inúmeras janelas de tempo, ou inúmeras frequências faltando. É dessa forma que, em situações de escuta da fala em presença concomitante de ruído, a mensagem do interlocutor será percebida e interpretada pelo ouvinte ${ }^{(1,2)}$.

A dificuldade em reconhecer sons da fala em ambientes ruidosos aumenta com o avanço da idade. A perda auditiva sensorial, comum na população idosa, é referida como uma das causas de dificuldade do idoso em reconhecer sons da fala ${ }^{(3,2)}$. No entanto, estudos apontam que independentemente de qualquer déficit na sensibilidade auditiva, idosos com audição dentro dos padrões de normalidade, quando comparados a jovens ouvintes, apresentam maior dificuldade no reconhecimento da fala em ambientes ruidosos ${ }^{(2,4,5,6)}$.

Sabe-se que o mascaramento temporal está relacionado à dificuldade em reconhecer a fala em ambientes ruidosos ${ }^{(7,8)}$ O mascaramento temporal caracteriza-se pela mudança de limiar de um som na presença de outro estímulo subsequente. Isto ocorre quando um estímulo é apresentado com duração e intensidade suficientes para reduzir a sensibilidade de um outro estímulo $^{(9)}$.

Estudos mostram que o efeito do mascaramento temporal é maior em idosos com limiares auditivos normais, quando comparados à jovens, também de audição normal ${ }^{(10,11,12,13)}$. Percebe-se portanto, que o mascaramento temporal está relacionada à maior dificuldade do idoso em reconhecer a fala em ambientes ruidosos ${ }^{(14)}$. No entanto, uma questão ainda não compreendida é se existe algum outro fator, além do efeito do mascaramento temporal, pode estar relacionado à essa dificuldade.

Uma possibilidade seria o declínio natural da habilidade de reconhecer a fala em baixa redundância. Mais especificamente, nesse caso, a fala intermitente (segmentada em tempo), semelhante à fala percebida por ouvintes em ambientes ruidosos. Surge, então, a pergunta 
condutora do presente estudo: será que a habilidade de reconhecer a fala intermitente naturalmente declina em função da idade?

A hipótese é que a habilidade de reconhecer a fala intermitente decline com o avanço da idade. Talvez, uma queda no desempenho dessa habilidade possa, inclusive, ser identificada em adultos de meia idade, que ainda não atingiram a senescência. Essa hipótese será testada nesse estudo através da comparação do desempenho de três grupos etários (jovens, adultos de meia idade e idosos) em testes de reconhecimento da fala intermitente (segmentada em tempo). Caso seja observado que a habilidade de reconhecer a fala intermitente decline com a idade, sugere-se direcionamento de ações preventivas e de intervenção voltadas para uma saudável sociabilidade das pessoas.

O estudo justifica-se por ser a audição peça fundamental para comunicação das pessoas em ambientes de interação social, e principalmente, pelo aumento das dificuldades auditivas e desafios relacionados à sociabilização dos idosos. Esses fatores fizeram com que nos últimos anos, o interesse de estudiosos sobre o assunto aumentasse ${ }^{(7,8,15,16)}$. Dessa forma, o presente estudo teve como objetivo investigar o reconhecimento auditivo da fala intermitente em função de diferentes taxas de modulação e em função da idade.

\section{MÉTODOS}

Trata-se de um estudo observacional, analítico e transversal. A amostra foi composta por 56 participantes e dividida em três grupos: Grupo 01: composto por vinte jovens com idade entre 18 - 25 anos (idade média de 21 anos), ambos os gêneros (sendo 12 do gênero feminino); Grupo 02: composto por vinte adultos de meia idade com idade entre 45 -55 anos (idade média de 48 anos), ambos os gêneros (sendo 16 do gênero feminino); Grupo 03: composto por 16 idosos com idade a partir de 60 anos (idade média de 65 anos), ambos os gêneros (sendo 14 do 
gênero feminino). Todos os participantes apresentarem limiares audiométricos até $25 \mathrm{~dB}$ NA, nas frequências de 250 à $4000 \mathrm{~Hz}$, em pelo menos uma orelha (Figura 1).

A amostra foi recrutada por conveniência. Foram excluídos do estudo indivíduos que apresentaram diagnóstico de qualquer alteração no sistema auditivo, bem como, diagnóstico ou queixa de qualquer alteração neurológica ou psiquiátrica que pudesse interferir em qualquer grau na comunicação oral.

Os indivíduos foram convidados a participar do estudo e, foram apresentados a todos os objetivos e procedimentos da pesquisa, incluindo explicação dos riscos e benefícios de sua participação. Após aceitarem participar da pesquisa, os participantes assinaram um Termo de Consentimento Livre e Esclarecido (TCLE) e, em data agendada, foram submetidos a audiometria tonal, que serviu como instrumento de inclusão, como descrito anteriormente.

As sentenças utilizadas no estudo fazem parte da versão brasileira do Hearing in Noise Test $(\mathrm{HINT})^{(17)}$. Essa versão do HINT é composta por sentenças em Português Brasileiro de uso cotidiano. São doze listas com vinte sentenças cada, todas foneticamente balanceadas. Adotouse a regra de nunca repetir sentença para o mesmo participante, eliminando a chance de aprendizado.

As sentenças foram acusticamente modificadas através do processador de fala da marca Tucker Davis Technology, modelo RZ6 e do programa MATLAB ${ }^{\mathrm{TM}}$ (Matrix Laboratory). A segmentação temporal foi realizada através da modulação da amplitude do sinal acústico, realizada por um modulador de onda quadrática (square-wave modulator). As sentenças foram moduladas em 100\% (limitação total de amplitude), resultando em um som de fala interrompida, ou intermitente. A fala intermitente foi apresentada em três condições (taxas) de modulação: $4 \mathrm{~Hz}, 10 \mathrm{~Hz}$ e $64 \mathrm{~Hz}$. Na condição de modulação em $4 \mathrm{~Hz}$, a cada segundo de sentença apresentada houve quatro períodos nos quais a amplitude foi diminuída em 100\% (ciclo de modulação). Cada um dos ciclos de modulação durou 250 ms, e por ter sido modulado 
em uma onda quadrática, metade desse tempo $(125 \mathrm{~ms})$ foi caraterizado com ausência de informação acústica. Portanto, para cada segundo de fala, apenas metade desse tempo (500 ms) conteve a informação verbal da sentença. A figura abaixo ilustra a segmentação em 4 Hz: os blocos azuis representam o período de tempo com presença de informação verbal, e os espaços vazios representam os períodos de tempo sem informação acústica.

Nas demais taxas de modulação, seguiu-se a mesma programação. Na modulação de 10 Hz, houve dez períodos de baixa de amplitude (ausência de informação acústica) e cada um durou 50 ms. Em $64 \mathrm{~Hz}$, os sessenta e quatro períodos de ausência de informação duraram 8 milissegundos cada um. Percebe-se que o tempo total de ausência de informação é o mesmo nas três condições de teste (500 ms para cada segundo), no entanto, o que difere é a distribuição entre os períodos com e sem ausência de som.

Os participantes que atenderam aos critérios de inclusão foram convidados a prosseguir e realizar os testes com a fala intermitente. Para a realização do teste de fala, o participante foi posicionado sentado dentro de uma cabina acústica e recebeu, através de fone auditivo Sennheiser HD580, o estímulo de fala. Foi escolhida para o teste a orelha de melhor audição ou a orelha direita, quando ambas apresentarem acuidade auditiva semelhante. Os participantes foram instruídos a repetir as sentenças como escutaram, mesmo que nem todas as palavras fossem inteligíveis.

O pesquisador, localizado fora da cabina acústica, controlou o material de fala utilizado no teste, monitorou e registrou os erros cometidos pelos participantes. À medida em que cada sentença era apresentada, o texto aparecia na tela do computador do pesquisador, com todas as palavras em destaque num retângulo sombreado sensível à marcação. O pesquisador utilizou o mouse do computador para marcar as palavras omitidas ou repetidas incorretamente.

Em cada condição testada foram utilizadas 25 sentenças, apresentadas de forma randomizada entre os participantes. A randomização na apresentação das sentenças foi realizada 
para eliminar um possível efeito do material linguístico nos resultados. Exemplificando: o participante 1 foi testado na condição de $4 \mathrm{~Hz}$ com 25 sentenças, iniciando na lista 1, sentença 1 até a lista 2 sentença 5 . O próximo participante começou na lista 2 , sentença 6 , até a lista 3 , sentença 10, e assim por diante. O mesmo acontece em todas as condições de teste.

Através do programa MATLAB, foram determinados índices de acertos para cada condição testada. O cálculo foi realizado de acordo com a quantidade de palavras utilizadas nas vinte e cinco sentenças testadas (o total de palavras variou entre as condições, já que as sentenças eram diversificadas quanto a sua quantidade de caracteres).

Para cada participante, e em cada condição de teste (4, 10 e $64 \mathrm{~Hz})$, foram determinados três índices de acerto no reconhecimento das sentenças. Posteriormente, foi realizada a média aritmética dos três resultados de cada condição de modulação, sendo essa média o resultado considerado para análise estatística.

Durante o teste, o pesquisador não forneceu qualquer pista ao participante em relação a seu desempenho. Intervalos para descanso foram realizados sempre que necessário.

A análise dos dados foi realizada pelos softwares STATA/SE 12.0 e Excel 2010. Todos os testes foram aplicados com $95 \%$ de confiança.

Para verificar a normalidade dos dados, utilizou-se o teste de Kolmogorov-Smirnov para variáveis quantitativas, e como resultados, obtivemos: para $4 \mathrm{~Hz}$ as variáveis estão normalmente distribuídas, já para $10 \mathrm{~Hz}$ e 64 Hz apresentam distribuição não normal.

Portanto, para investigação do efeito da taxa de modulação foi realizada a análise de variância (ANOVA) com Post Hoc de Tukey (Distribuição Normal) e Kruskal Wallis com comparação múltipla de Dunn’s (para a Distribuição não Normal).

Para a investigação do efeito da idade, utilizou-se um método para medidas repetidas: o modelo de regressão linear misto, que leva em consideração a possível correlação entre os valores da variável resposta que constituem medidas repetidas. 


\section{RESULTADOS}

Os percentuais de reconhecimento para fala segmentada em tempo foram descritos em função dos grupos etários e em função da taxa de modulação.

Para fins de investigação do efeito da idade, inicialmente, os dados foram analisados quanto a sua distribuição de normalidade. Esses resultados estão descritos na Tabela 1. Os dados mostram diferença significativa entre adultos jovens e idosos, e entre adultos de meia idade e idosos. Observa- se que o grupo de adultos jovens tiveram desempenho semelhante ao grupo de adultos de meia idade em todas as condições de teste $(4 \mathrm{~Hz}, 10 \mathrm{~Hz}$ e $64 \mathrm{~Hz})$.

Os resultados da análise do efeito da taxa de modulação no reconhecimento da fala segmentada estão descritos na Tabela 2.

Ao se comparar as médias das taxas de modulação de todos os participantes (jovens, adultos de meia idade e idosos) percebe-se diferença significativa entre as três taxas testadas. No entanto, quando se compara os resultados entre as taxas de modulação em cada grupo etário isoladamente, percebe-se que apenas para os adultos de meia idade não houve diferença significativa entre as taxas de $10 \mathrm{~Hz}$ e $64 \mathrm{~Hz}$.

\section{DISCUSSÁO}

Umas das hipóteses do presente estudo é de que exista um efeito da idade no reconhecimento da fala intermitente. Ou seja, a hipótese é que, devido ao declínio em habilidades do processamento temporal, indivíduos com mais idade apresentem maior dificuldade em reconhecer a fala segmentada em tempo. Os achados aqui encontrados corroboram com essa hipótese. Em todas as taxas de modulações testadas, as médias de percentual de acerto diminui com o aumento da idade. 
Shafiro et al., ${ }^{(18)}$ investigaram a influência da idade e da perda auditiva na inteligibilidade da fala interrompida. As sentenças foram moduladas em taxas entre $0,5 \mathrm{a} 8 \mathrm{~Hz}$, e os resultados demonstraram efeitos altamente dependentes da idade e perda auditiva na percepção da fala interrompida.

Num estudo desenvolvido em $2012^{(20)}$, com o intuito de investigar o efeito da idade e da perda auditiva no reconhecimento de palavras interrompidas, foram apresentadas a jovens de audição normal e a idosos com e sem perda auditiva, palavras-alvo do teste SPIN isoladamente e no contexto da sentença original, utilizando uma série de padrões de interrupção em que partes da fala foram substituídas por silêncio. Os resultados demonstraram que tanto a idade quanto a perda auditiva afetam a percepção da fala interrompida. Os achados do nosso estudo corroboram com o padrão descrito no estudo mencionado no que diz respeito ao efeito da idade, já que em nossa amostra não houve participantes com perda auditiva. Ou seja, em ambos os estudos, os resultados foram melhores para os grupos de menor idade quando comparado aos idosos.

O efeito da idade na audição periférica e central de idosos é amplamente documentado. Alterações fisiológicas no sistema auditivo do idoso, assim como dificuldades cognitivas e de memória, explicam o declínio em habilidades no processamento de sons, especialmente, no reconhecimento da fala em ambientes ruidosos ${ }^{(5,20,21,22)}$.

Em estudo realizado em 2014, participantes idosos não obtiveram bom desempenho nas tarefas cognitivas utilizando fonemas degradados. Porém a população alvo apresentava presbiacusia e por esta razão não foi possível determinar se a falta de compensação se deu em função das limitações periféricas ou centrais ${ }^{(21)}$. No presente estudo, os participantes não apresentaram perda auditiva e ainda assim obtiveram desempenho inferior quando comparados aos jovens e adultos de meia idade utilizando sentenças. 
Sabe-se que o declínio na sensibilidade auditiva decorrente da presbiacusia tem papel significante no reconhecimento de fala, principalmente quando se trata de fala de baixa redundância. Porém, no presente estudo, apenas dois participantes idosos apresentaram limiares piores que 25 dB NA nas frequências de 6000 e 8000 Hz. As médias dos limiares dos idosos nessas frequências, apesar de piores quando comparadas aos demais grupos estudados, foram melhores que $25 \mathrm{~dB}$ NA.

Não se sabe exatamente quando, ou em que faixa etária, as dificuldades provocadas pela idade começam a acontecer. Nesse sentido, os resultados aqui encontrados para o grupo de adultos de meia idade caracterizam um achado interessante. Os resultados encontrados para esse grupo, nas três condições de teste, são semelhantes aos resultados dos adultos jovens, e diferem da média dos idosos. A proximidade desse grupo com o grupo de jovens, em termos de desempenho no reconhecimento da fala segmentada, levanta a ideia de que possivelmente um declínio nas habilidades necessárias para o fechamento das informações acústicas ausentes numa fala intermitente não tenha início até pouco antes da senescência.

Ao contrário do que foi encontrado aqui, Grose, Mamo e Hall ${ }^{(12)}$ apontam para o surgimento de déficits de processamento temporal relativamente cedo no processo de envelhecimento. O artigo publicado faz um breve levantamento de estudos com ouvintes normais, adultos de meia idade, e conclui que alterações no processamento auditivo se iniciam antes da senescência.

Apesar de tantas dificuldades referentes a escuta dos idosos em ambientes sociais ruidosos, existem aspectos positivos decorrentes do avanço da idade. Acredita-se que pessoas de mais idade possam superar, nem que seja parcialmente, suas dificuldades auditivas, devido a sua experiência linguística. A competência linguística aumenta ao longo do tempo de vida. A experiência na pragmática e semântica da sua língua, promovem mecanismos cognitivos 
compensatórios que ajudam na comunicação em ambientes sonoros complexos, podendo influenciar a percepção da fala interrompida ${ }^{(21,23,24)}$.

Isso é consistente com a ideia de que processos top-down utilizando informações parciais podem ajudar a preencher informações perdidas, facilitar o foco atencional e o processamento de baixo para cima que fornece informações cruciais sobre o sinal de fala ${ }^{(25)}$.

A segunda hipótese desse estudo foi que o aumento da taxa de modulação da fala intermitente favorecesse o reconhecimento da fala em grupos de indivíduos ouvintes, independente da faixa etária. Para investigação do chamado efeito da taxa de modulação, foi feita uma comparação de média de percentuais de acerto entre as taxas testadas em todos os participantes. O padrão de respostas encontrado confirma a hipótese. A medida em que a taxa de modulação aumenta, os percentuais de acerto aumentam nos três grupos testados.

A melhora no reconhecimento de uma fala intermitente com uma frequência maior de taxa de modulação pode ser explicada pelo menor intervalo de tempo com ausência de informação acústica provocada em taxas mais altas. Ou seja, a medida em que a taxa aumenta, o número de cortes de informação acústica aumenta num mesmo intervalo de tempo (1 segundo). Por exemplo, em $4 \mathrm{~Hz}$ ocorrem quatro 'cortes' em um segundo, e em $64 \mathrm{~Hz}$, ocorrem sessenta e quatro cortes. Embora nas taxas mais altas exista maior quantidade de cortes de informação acústica, esses cortes são mais breves, e por isso, menos informação acústica é retirada da frase, facilitando a compreensão. Por outro lado, mais informação acústica é retirada da frase segmentada em taxas mais baixas de modulação.

Esse efeito parece ser mais significante em taxas menores que $10 \mathrm{~Hz}$, no caso aqui investigado, em $4 \mathrm{~Hz}$. Isso porque em $10 \mathrm{~Hz}$ e em $64 \mathrm{~Hz}$ os percentuais de acerto foram elevados (de $88,72 \%$ a 99,69\%), próximos de uma situação ideal de escuta, e os valores obtidos em $4 \mathrm{~Hz}$ foram inferiores a $74 \%$, chegando a $55,92 \%$ (reconhecimento de pouco mais que a metade do que foi dito) no grupo de idosos. Essa linha de raciocínio explica também a semelhança dos 
resultados obtidos entre 10 e $64 \mathrm{~Hz}$ no grupo de idosos. Possivelmente um número maior de participantes apontasse uma diferença significantes entres as taxas de modulação, no entanto, provavelmente ambas apresentariam percentuais de acerto bem superiores quando comparadas a taxa de $4 \mathrm{HZ}$.

O desempenho tende a ser menor em taxas de interrupção lenta, nesse caso $4 \mathrm{~Hz}$, quando os ouvintes precisam preencher em trechos mais longos de fala perdida. Assim, a ausência de fragmentos mais longos pode resultar em maior incerteza lexical e tornar mais difícil o benefício de pistas contextuais.

A tarefa de reconhecer a fala em presença de ruído mascarante que oscila em amplitude pode ser semelhante à tarefa de reconhecer a fala segmentada em tempo, pois em ambas as situações o ouvinte se depara com ausência de informações acústicas da frase alvo. No entanto, embora exista uma semelhança na situação de escuta de baixa redundância entre as duas condições de teste, a presença do ruído mascarante provoca o efeito de pós-mascaramento (forward masking) e pré-mascaramento (backward masking), onde as informações acústicas da fala nos intervalos de tempo de baixa amplitude do ruído ainda recebem interferência do ruído mascarante. Nessa situação, os intervalos de tempo com presença de informação de fala ficam ainda mais diminuídos do que o presumido ao analisarmos apenas a taxa de modulação.

Advíncula e colaboradores ${ }^{(26)}$ investigaram o desempenho de jovens ouvintes no reconhecimento de sentenças (teste HINT na versão brasileira) em presença de ruído mascarante oscilando em diferentes taxas de modulação: 4 Hz, 8 Hz, 10 Hz, 16 Hz, 32 Hz e 64 Hz. Os achados mostram desempenho semelhante para as taxas de $4 \mathrm{~Hz}$ até $32 \mathrm{~Hz}$, e os resultados na condição de $64 \mathrm{~Hz}$ foi pior que as demais taxas investigadas. Importante notar que o padrão encontrado por eles é inverso ao padrão encontrado no presente estudo, pois a modulação ocorreu no ruído mascarante e não na fala propriamente dita. Portanto, em presença 
de ruído modulado, o desempenho no reconhecimento da fala piora na medida em que a taxa de modulação aumenta.

Embora os padrões sejam inversos, a lógica é a mesma. Os autores explicam que a taxa maior (64 HZ) torna o ruído modulado fisicamente mais próximo ao ruído estável. Ou seja, os intervalos de tempo nos quais o ruído diminui em amplitude são menores, dificultando a percepção dos sinais acústicos da fala. Os resultados aqui encontrados seguem essa mesma linha de raciocínio. Melhores percentuais de reconhecimento de fala são encontrados para as condições de teste com menos perda de informação acústica.

Neste trabalho, foi possível observar que idosos com audição normal possuem comportamento distintos dos jovens e adultos de meia idade com a mesma característica audiométrica. Ao mesmo tempo em que se sabe que estudos reforçam o raciocínio de que déficit do processamento auditivo temporal está relacionado à dificuldade dos idosos em reconhecer a fala em ambientes ruidosos, este estudo sugere que novas pesquisas, com um número maior de participantes, utilizando o mesmo material de fala (a versão brasileira do HINT) segmentado em tempo e que investiguem aspectos auditivo e cognitivos, possam contribuir para a melhor compreensão desta habilidade auditiva no senescente.

\section{CONCLUSÃO}

Os achados mostram um efeito da idade no reconhecimento da fala segmentada: indivíduos com mais idade apresentaram maior dificuldade em reconhecer a fala segmentada em tempo.

Percebe-se ainda um efeito de taxa de modulação nos três grupos etários: quanto maior a taxa, melhor o desempenho. 


\section{REFERÊNCIAS}

1. Carhart R, Tillman TW, Greetis ES. Perceptual masking in multiple sound background. J Acoust Soc Am. 1969;45(3):694-703.

2. Caporali AS, Silva, JA. Reconhecimento de fala no ruído em jovens e idosos com perda auditiva. Rev Bras Otorrinolaringol. 2004;70(4):525-32.

3. Humes LE, Christopherson L. Speech identification difficulties in hearing-impaired elderly persons: the contribution of auditory processing deficits. J Speech Hear Res. 1991;34:686-93.

4. Versfeld N, Dreschler W. The relationship between time-compressed speech and speech in noise in young and elderly listeners. J Acoust Soc Am. 2002;111(1):401-8.

5. Gordon-Salant S. Speech perception and auditory temporal processing performance by older listeners: Implications for real-world communication. Seminars in Hearing. 2006;27(4):26468 .

6. Desloge JG, Reed CM, Braisa LD, Perez ZD, Delhorn LA. Speech reception by listeners with real and simulated impairment: effects of continuous and interrupted noise. J Acoust Soc Am. 2010;128(1):342-59.

7. Grose J, Mamo S; Processing of temporal fine structure as a function of age. Ear Hear. 2010;31(6):755-760.

8. Hall JW, Buss E, Grose JH, Roush PA. Effects of age and hearing impairment on the ability to benefit from temporal and spectral modulation. Ear Hear. 2012;33(3):340-48.

9. Shinn JB. Temporal processing: the basics. Hear J. 2003:56(7):52.

10. George EL, Zekveld AA, Kramer SE, Goverts ST, Festen JM, Houtgast T. Auditory and nonauditory factors affecting speech reception in noise by older listeners. J Acoust Soc Am. 2007;121(4):2362-75.

11. Gifford RH, Bacon SP, Williams EJ. An examination of speech recognition in a modulated background and of forward masking in younger and older listeners. J Speech Lang Hear Res. 2007;50(4):857-64.

12. Grose JH, Mamo SK, Hall JW. Age effects in temporal envelope processing: speech unmasking and auditory steady state responses. Ear Hear. 2009;30(5):568-75.

13. Wilson RH, McArdle R, Betancourt MB, Herring K, Lipton T, Chisolm TH. Wordrecognition performance in interrupted noise by young listeners with normal hearing and older listeners with hearing loss. J Am Acad Audiol. 2010;21(2):90-109.

14. Grose JH, Porter HL, Buss E. Aging and Spectro-Temporal Integration of Speech. Trends Hear. 2016;20:1-11.

15. Grose JH, Mamo S. Electrophysiological measurement of binaural beats: effects of primary tone frequency and observer age. Ear and Hear. 2012;32(2):187-94. 
16. Calais LL, Lima-Gregio AM, Costa MJ, Gil D, Borges ACLC. Reconhecimento de fala em idosos: proposta de um teste considerando a previsibilidade da palavra. Audiol Commun Res. 2016;21:1-9.

17. Bevilacqua MC, Banhara M, Costa E, Vignoly A, Alvarenga KF. The Brazilian Portuguese hearing in noise test. Int J Audiol. 2008;47(6):364-365.

18. Shafiro V, Sheft S, Risley R, Gygi B. Effects of age and hearing loss on the intelligibility of interrupted speech. J Acoust Soc Am. 2015;137(2):745-56.

19. Kidd G R, Humes L E. Effects of age and hearing loss on the recognition of interrupted words in isolation and in sentences. J Acoust Soc Am. 2012;131(2):1434-1448.

20. Gordon-Salant S, Fitzgibbons PJ. Recognition of Multiply Degraded Speech by Young and Elderly Listeners. J Speech Hear Res. 1995;38(5):1150-1156.

21. Saija JD, Akyurek EG, Angringa TC, Baskente D. Perceptual Restoration of Degraded Speech Is Preserved with Advancing Age. J Assoc Res Otolaryngol. 2014;15(1):139-48.

22. Parra VM. Iório MCM, Mizahi MM, Baraldi, GS. Testes de padrão de frequência e de duração em idosos com sensibilidade auditiva normal. Rev Bras Otorrinolaringol. 2004;70(4):517-23.

23. Benard MR, Mensink JS, Başkent D. Individual differences in top-down restoration of interrupted speech: Links to linguistic and cognitive abilities. J Acoust Soc Am. 2014:135(2).

24. Jin SH, Nelson PB. Interrupted speech perception: The effects of hearing sensitivity and frequency resolution. J Acoust Soc Am. 2010;128(2):881-89.

25. Gary RK, Larry EH. Effects of age and hearing loss on the recognition of interrupted words in isolation and in sentences. J Acoust Soc Am. 2012;131(2): 1434-48.

26. Advíncula KP, Menezes DC, Pacífico FA, Griz SMS. Percepção da fala em presença de ruído competitivo: o efeito da taxa de modulação do ruído mascarante. ACR. 2013;18(4):23844. 


\section{TABELAS}

Tabela 1 - Comparação entre as médias dos percentuais de reconhecimento de fala entre as diferentes faixas etárias.

\begin{tabular}{ccccc}
\hline & \multicolumn{3}{c}{ Faixa Etária } & \\
\cline { 2 - 4 } Frequências & Jovens & Adultos & Idosos & p-valor \\
& Média \pm DP & Média \pm DP & Média \pm DP & \\
\hline $4 \mathrm{~Hz}$ & $73,98 \pm 7,43$ & $69,54 \pm 15,53$ & $55,92 \pm 16,06^{\mathrm{AB}}$ & $0,001 *$ \\
$10 \mathrm{~Hz}$ & $94,80 \pm 3,27$ & $90,36 \pm 17,31$ & $88,72 \pm 10,27^{\mathrm{AB}}$ & $0,013^{* *}$ \\
$64 \mathrm{~Hz}$ & $99,69 \pm 0,39$ & $98,98 \pm 2,38$ & $98,61 \pm 1,30^{\mathrm{AB}}$ & $0,008^{* *}$ \\
& & & & \\
\hline
\end{tabular}

(*) ANOVA (**) Kruskal-Wallis

(A) Diferença estatisticamente significativa em relação aos jovens.

(B) Diferença estatisticamente significativa em relação aos adultos. 
Tabela 2 - Comparação das médias dos percentuais de reconhecimento de fala segmentada entre as diferentes taxas de modulação.

\begin{tabular}{|c|c|c|c|c|}
\hline \multirow{3}{*}{ Variáveis } & \multicolumn{3}{|c|}{ Frequências } & \multirow{3}{*}{ p-valor * } \\
\hline & $4 \mathrm{~Hz}$ & $10 \mathrm{~Hz}$ & $64 \mathrm{~Hz}$ & \\
\hline & Média \pm DP & Média \pm DP & Média \pm DP & \\
\hline \multicolumn{5}{|l|}{ Todos } \\
\hline Participantes & $67,24 \pm 15,11$ & $91,48 \pm 11,95^{\mathrm{A}}$ & $99,13 \pm 1,63^{\mathrm{AB}}$ & $<0,001$ \\
\hline \multicolumn{5}{|l|}{ Faixa Etária } \\
\hline Jovens & $73,98 \pm 7,43$ & $94,80 \pm 3,27^{\mathrm{A}}$ & $99,69 \pm 0,39 \mathrm{AB}$ & $<0,001$ \\
\hline Adultos & $69,54 \pm 15,53$ & $90,36 \pm 17,31^{\mathrm{A}}$ & $98,98 \pm 2,38^{\mathrm{A}}$ & $<0,001$ \\
\hline Idosos & $55,92 \pm 16,06$ & $88,72 \pm 10,27^{\mathrm{A}}$ & $98,61 \pm 1,30^{\mathrm{AB}}$ & $<0,001$ \\
\hline
\end{tabular}

(*) Medidas Repetidas

(A) Diferença estatisticamente significativa em relação a $4 \mathrm{~Hz}$.

(B) Diferença estatisticamente significativa em relação a $10 \mathrm{~Hz}$. 


\section{FIGURAS}

Figura 1 - Representação gráfica das médias dos limiares audiométricos das orelhas testada para os três grupos etários.

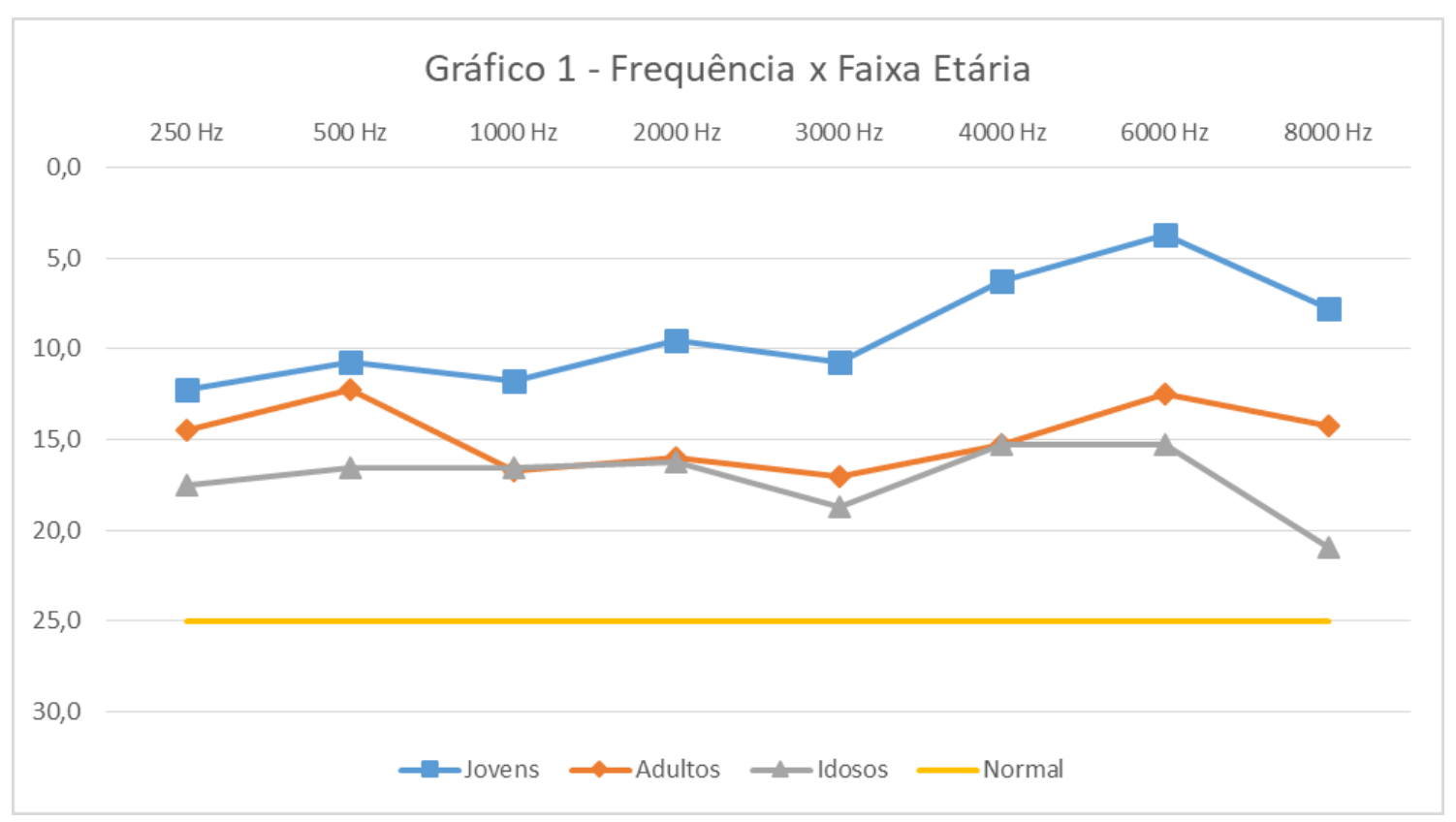


Figura 2 - Ilustração da fala segmentada em $4 \mathrm{~Hz}$.

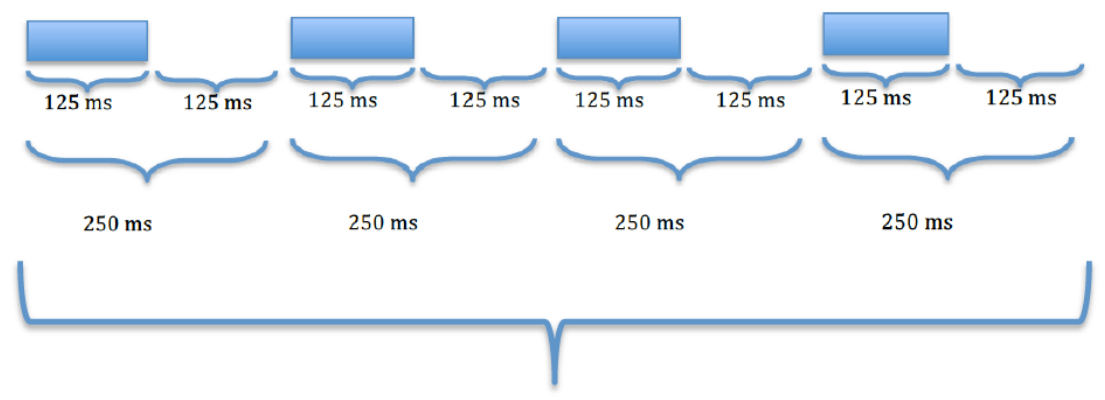

1 segundo 


\section{CONSIDERAÇÕES FINAIS}

Os achados mostram um efeito da idade no reconhecimento da fala segmentada: indivíduos com mais idade apresentaram maior dificuldade em reconhecer a fala segmentada em tempo.

Percebe-se ainda um efeito de taxa de modulação nos três grupos etários: quanto maior a taxa, melhor o desempenho. 


\section{REFERÊNCIAS}

ADVÍnCUlA, K. P.; MENEZES, D. C.; PACÍFICO, F. A.; COSTA, M. L. G.; GRIZ, S. M. S. Efeito da idade no processamento auditivo temporal: benefício da modulação do mascaramento e efeito do pós-mascaramento. ACR, São Paulo, v.23, p.1-6, 2018.

ADVÍNCULA, K. P.; MENEZES, D. C.; PACÍFICO, F. A.; GRIZ, S. M. S. Percepção da fala em presença de ruído competitivo: o efeito da taxa de modulação do ruído mascarante. ACR, São Paulo, v.18, n.4, p.238-44, 2013.

AMERICAN SPEECH-LANGUAGE-HERING ASSOCIATION (ASHA). (Central)

Auditory processing disorders. Technical Report. 2005.

Disponível em: <http://www.asha.org/members/deskref-journals/deskref/default>

Acessado em: 11 de outubro de 2017.

ANDERSON, S.; SKOE, E.; CHANDRASEKARAN, B.; KRAUS, N. Neural timing is linked to speech perception in noise. J Neurosci., v.30, n.14, p.4922-26, 2010.

BARAN, J. A.; MUSIEK, F. E. Avaliação comportamental do sistema nervoso auditivo central. In: MUSIEK, F. E.; RINTELMANN, W. F. Perspectivas atuais em avaliação auditiva. São Paulo: Manole, 2001. cap. 13, p. 371-409.

BECKER, K. T.; COSTA, M. J.; LAUTENSCHLAGER, L.; TOCHETTO, T. M.; SANTOS, S. N. Reconhecimento de fala em indivíduos com e sem queixa clínica de dificuldade para entender a fala no ruído. Arq Int Otorrinolaringol / Intl Arch Otorhinolaryngol., São PauloBrasil, v.15, n.3, p.276-82, 2011.

BELLIS, T. J. Assessment and management of central auditory processing disorders in the educational setting: from science to practice (2nd ed.). Clifton Park, NY: Thomson Learning, Inc, 2003.

BENARD, M. R.; MENSINK, J. S.; BAȘKENT, D. Individual differences in top-down restoration of interrupted speech: links to linguistic and cognitive abilities. J Acoust Soc Am., v.135, v.2, 2014.

BERNSTEIN J. G.; SUMMERS, V.; IYER, N.; BRUNGART, D.S. Set-size procedures for controlling variations in speech-reception performance with a fluctuating masker. J Acoust Soc Am., v.132, p.2676-89, 2012. 
BERTOLI, S.; SMURZYNSKY, J.; PROBST, R. Temporal resolution in young and elderly subjects as measured by mismatch negativity and a psychoacoustic gap detection task. Clinical Neurophysiology., v.113, n.3, p.396-406, 2002.

BESS, F. H.; HEDLEY-WILIAMS, A.; LICHTENSTEIN. Avaliação audiológica dos idosos. In: MUSIEK, F. E.; RINTELMANN. W. F. Perspectivas atuais em avaliação auditiva. 1. ed. Barueri-SP: Manole, 2001. p.343-69.

BEVILACQUA, M. C.; BANHARA, M. R.; COSTA, E. A.; VIGNOLY, A. B.; ALVARENGA, K. F. The Brazilian Portuguese hearing in noise test. Int J Audiol., v.47, n.6, p.364-65, 2008.

BHARGAVA, P.; GAUDRAIN, E.; BASKENT, D. The intelligibility of interrupted speech: cochlear implant users and normal hearing listeners. J Assoc Res Otolaryngol., v.17, n.5, p.475-91, 2016.

BRONKHORST, A. W.; PLOMP, R. A Clinical test for the assessment of binaural speech perception in noise. Audiology, v.29, p.275-85, 1990.

BUZO, B. C.; LOPES, J. A. S. Reconhecimento de fala no ruído em sujeitos com audição normal e queixa de zumbido. Audiol Commun Res, v.22, p.1-7, 2017.

CAHART, R.; TILLMAN, T.; GREETIS, E. Perceptual masking in multiple sound background. J Acoust Soc Am., v.45, n.3, p. 694-703, 1969.

CALAIS, L. L.; LIMA-GREGIO, A. M.; COSTA, M. J.; GIL, D.; BORGES, A. C. L. C. Reconhecimento de fala em idosos: proposta de um teste considerando a previsibilidade da palavra. Audiol Commun Res., v.21, p.1-9, 2016.

CALAIS, L. L.; RUSSO, I. C. P.; BORGES, A. C. L. C. Desempenho de idosos em um teste de fala na presença de ruído. Pró-Fono R Atual Cient., v.20, n.3, p.174-52, 2008.

CAPORALI, S.; SILVA, J. Reconhecimento de fala no ruído em jovens e idosos com perda auditiva. Rev Bras Otorrinolaringol., v.70, n.4, p.525-32, 2004.

CERVERA, T.; GONZALEZ-ALBERNAZ, J. Test of Spanish sentences to measure speech intelligibility in noise conditions. Behav Res., v.43, n.2, p.459-67, 2011. 
DESLOGE, J. G.; REED, C. M.; BRAISA, L. D.; PEREZ, Z. D.; DELHORN, L. A. Speech reception by listeners with real and simulated impairment: effects of continuous and interrupted noise. J Acoust Soc Am., v.128, n.1, p.342-59, 2010.

DIRKS, D. D; BOWER, D. Effect of forward and backward masking on speech intelligibility. J Acoust Soc Am., v.47, n.4, p.1003-8, 1970.

EGGERMONT, J. J. Neural responses in primary auditory cortex mimic psycophysical, across- frequency-channel, gap detection thresholds. J Neurophysiol., v.84, n.3, p.1453-63, 2000.

FILIPPINI, R.; SCHOCHAT, E. Um novo paradigma para a avaliação do mascaramento temporal auditivo: um estudo piloto. CoDas, v.26, n.4, p.302-7, 2014.

FRISINA, D. R.; FRISINA, D. R. Speech recognition in noise and presbycusys: relations to possible neural mechanisms. Hear Res., v.106, n.1-2, p.95-104, 1997.

GARY, R. K.; LARRY, E. H. Effects of age and hearing loss on the recognition of interrupted words in isolation and in sentences. J Acoust Soc Am., v.131, n.2, p.143448, 2012.

GEORGE, E. L; ZEKVELD, A. A; KRAMER, S. E; GOVERTS, S. T.; FESTEN, J. M.; HOUTGAST, T. Auditory and nonauditory factors affecting speech reception in noise by older listeners. J Acoust Soc Am., v.121, n.4, p.2362-75, 2007.

GIFFORD, R. H; BACON, S. P; WILLIAMS, E. J. An examination of speech recognition in a modulated background and of forward masking in younger and older listeners. J Speech Lang Hear Res., v.50, n.4, p.857-64, 2007.

GORDON-SALANT, S. Speech perception and auditory temporal processing performance by older listeners: Implications for real-world communication. Semin Hear., v.27, n.4, p.264-68, 2006.

GORDON-SALANT, S.; FITZGIBBONS, P. J. Recognition of multiply degraded speech by young and elderly listeners. J Speech Hear Res., v.38, n.5, p.1150-56, 1995.

GORDON-SALANT, S.; FITZGIBBONS, P. J.; YENI-KOMSHIAN, G. H. Auditory temporal processing and aging: implications for speech understanding of older people. Audiol Res., v.1, n.1, p.9-15, 2011. 
GROSE, J. H.; MAMO, S. K.; HALL, J.W. Age effects in temporal envelope processing: speech unmasking and auditory steady state responses. Ear Hear., v.30, n.5, p.568-75, 2009.

GROSE J. H.; MAMO, S; Electrophysiological measurement of binaural beats:Effects of primary tone frequency and observer age. Ear and Hear., v.32, n.2, p.187-194, 2012.

Processing of temporal fine structure as a function of age.

Ear Hear., v.31, n.6 p.755-60, 2010.

GROSE, J. H.; PORTER, H. L; BUSS, E. Aging and spectro-temporal integration of speech. Trends Hear., v.20, p.1-11, 2016.

HALL, J. W.; BUSS, E.; GROSE, J. G.; ROUSH, P. A. Effects of age and hearing impairment on the ability to benefit from temporal and spectral modulation. Ear Hear., v.33; n.3, p.340-348, 2012.

HULL, R. H. Atendimento ao paciente idoso. In: KATZ, J. Tratado de Audiologia clínica. $4^{\mathrm{a}}$ Ed. São Paulo: Manole; 1999. p. 783-91.

HUMES, L. E.; CHRISTOPHERSON, L. Speech identification difficulties in hearingimpaired elderly persons: the contribution of auditory processing deficits. J Speech Hear Res., v.34, p.686-693, 1991.

ISHII, C.; ARASHIRO, P. M.; PEREIRA, L. D. Ordenação e resolução temporal em cantores profissionais e amadores afinados e desafinados Pró-Fono R Atual Cient., Barueri, São Paulo, v.18, n.3, p.285-92, 2006.

IZQUIERDO, M. A.; OLIVER, D. L.; MALMIERCA, M. S. Mecanismos de plasticidad (funcional y dependiente de actividad) en el cerebro auditivo adulto y en desarrollo. Rev Neurol., v.48, n.8, p.421-29, 2009.

JIN, S. H.; NELSON, P. B. Interrupted speech perception: The effects of hearing sensitivity and frequency resolution. J Acoust Soc Am., v.128, n.2, p.881-89, 2010.

KRAUS, N.; NICOL, T. Aggregate neural response to speech sounds in the central auditory system. Speech Commun., v.41, n.1, p.35-47, 2003. 
LUCION, C. S.; OLIVEIRA, P. R. Transtorno do processamento auditivo: características e implicações na aprendizagem. Rev Roteiro, v.35, n.1, p.73-94, 2010.

LUZ, D. M.; COSTA-FERREIRA, M. I. D. Identificação dos fatores de risco para o transtorno do processamento auditivo (central) em pré-escolares. Rev CEFAC, v.13, n.4, p.657-67, 2011.

MILLER, G. A.; LICKLIDER, J. C. R. The intelligibility of interrupted speech. J Acoust Soc Am., v.22, n.2, p.167-73, 1950.

MOORE, B.C.J. An introduction to the psychology of hearing. San Diego, CA: Academic Press. $5^{\text {th }} ; 2003$.

MUNIZ, L. F.; ROAZZI, A.; SCHOCHAT, E.; TEIXEIRA, C. F.; LUCENA, J. A. Avaliação da habilidade de resolução temporal, com uso do tom puro, em crianças com e sem desvio fonológico. Rev CEFAC, v.6, n.4, p.550-62, 2007.

NELSON, P. B.; JIN, S. H. Factors affecting speech understanding in gated interference: cochlear implant users and normal-hearing listeners. J Acoust Soc Am., v.115, n.5, p.228694, 2004.

NEVES, V. T.; FEITOSA, M. A. G. Controvérsias ou complexidade na relação entre processamento temporal auditivo e envelhecimento? Rev Bras Otorrinolaringol., v.69, n.2, p.242-49, 2003.

PARRA, V. M.; IÓRIO, M. C. M.; MIZAHI, M. M.; BARALDI, G. S. Testes de padrão de frequência e de duração em idosos com sensibilidade auditiva normal. Rev Bras Otorrinolaringol., v.70, n.4, p.517-23, 2004.

PINHEIRO, M. M.; PEREIRA, L. D. Processamento auditivo em idosos: estudo da interação por meio de testes com estímulos verbais e não-verbais Rev Bras Otorrinolaringol., v.70, n.2, p.209-14, 2004.

PLACK, C; SKEELS, V. Temporal integration and compression near absolute threshold in normal and impaired ears. J Acoust Soc Am., v.122, n.4, p.2236-44, 2007.

RAWOOL, V. A. Temporal processing primer. Defining key concepts in temporal processing. Part 1. The Hearing Review, v.13, n.5, p.30-34, 2006. 
RECANZONE, G. H.; SUTTER, M. L. The biological basis of audition. Annu Rev Psychol., v.59, n.9, p.119-42, 2008.

JACOB, R. T. S.; MONTEIRO, N. F. G.; MOLINA, S. V.; BEVILACQUA, M. C.; LAURIS, J. R. P.; MORET, A. L. M. Percepção da fala em crianças em situação de ruído. Arq Int Otorrinolaringol. / Intl Arch Otorhinolaryngol., São Paulo, v.15, n.2, p.163-167, 2011.

SAIJA, J. D.; AKYUREK, E. G.; ANGRINGA, T. C.; BASKENTE, D. Perceptual restoration of degraded speech is preserved with advancing age. J Assoc Res Otolaryngol., v.15, n.1, p.139-148, 2014.

SAINT-EXUPERY, A. O pequeno príncipe. Rio de Janeiro: Agir, 2005

SAMELLI, A. G.; SCHOCHAT, E. Processamento auditivo resolução temporal e teste de detecção de gap: revisão de literatura. Rev CEFAC, São Paulo, v.10, n.3, p.369-77, 2008.

SBOMPATO, A. F.; CORTELETTI, L. C. B. J.; MORET, A. L. M.; JACOB, R. T. S. Hearing in Noise Test Brazil: standardization for young adults with normal hearing. Braz J Otorhinolaryngol., v.81, n.4, p.384-88, 2015.

SCHOCHAT, E. Avaliação do processamento auditivo: revisão da literatura. Rev Bras Med Otorrinolaringol., v.5, n.1, p.24-31, 1996.

SENS, P. M.; ALMEIDA, C. I. Participation of the cerebellum in auditory processing. Braz J Otorhinolaryngol., v.73, n.2, p.266-70, 2007.

SHAFIRO, V.; SHEFT, S.; RISLEY, R.; GYGI, B. Effects of age and hearing loss on the intelligibility of interrupted speech. J Acoust Soc Am., v.137, n.2, p.745-56, 2015.

SHIBATA, T.; SAKASHITA, T.; YAMANE, H.; HASHIMOTO, C. Temporal resolution and speech recognition ability of patients with retrocochlear auditory dysfunction. Acta Otolaryngol Suppl., v.554, p.30-34, 2004.

SHINN, J. B. Temporal processing and. temporal patterning tests. In: MUSIEK, F. E, CHERMAK, G. D. Handbook of (central) auditory processing disorder: suditory Neurocience and diagnosis. San Diego: plural publishing, 2007. p.231-256.

SHINN, J.B. Temporal processing: the basics. Hear J., v.56, n.7, p.52, 2003. 
SMITH, N. A.; TRAINOR, L. J.; SHORE, D. I. The development of temporal resolution: between-channel gap detection in infants and adults. J Speech Lang Hear Res., v.49, n.5, p.1104-13, 2006.

SNELL, K.; FRISINA, D. Relationships among age-related differences in gap detection and word recongnition. J Acoust Soc Am., v.107, n.3, p.1615-26, 2000.

TERTO, S. S. M.; LEMOS, S. M. A. Aspectos temporais auditivos: produção de conhecimento em quatro periódicos nacionais. Rev CEFAC, v.13, n.5, p.926-36, 2011.

VERSFELD, N.; DRESCHLER, W. The relationship between time-compressed speech and speech in noise in young and elderly listeners. J Acoust Soc Am., v.111, n.1, p.401-08, 2002.

WILSON, R. H; MCARDLE, R; BETANCOURT, M. B; HERRING, K; LIPTON, T; CHISOLM, T. H. Word-recognition performance in interrupted noise by young listeners with normal hearing and older listeners with hearing loss. J Am Acad Audiol., v.21, n.2, p.90-109, 2010.

WONG, P. C. M.; ETTLINGER, M.; SHEPPARD, J.; GUNASEKARAN, G.; DHAR, $\mathrm{S}$. Neuroanatomical characteristics and speech perception in noise in older adults. Ear Hear., v.31, n.4, p.471-9, 2010. 


\section{APÊNDICE A - TERMO DE CONSENTIMENTO LIVRE E ESCLARECIDO}

Convidamos o(a) Sr.(a) para participar como voluntário(a) da pesquisa "Integração espectro-temporal da fala em jovens, adultos e idosos", que está sob a responsabilidade da pesquisadora Denise Costa Menezes; Telefone: (81) 98133-1971; e-mail para contato: denicmenezes@gmail.com; Endereço: Rua conselheiro Nabuco, número 181, Casa Amarela Recife.

Caso este Termo de Consentimento contenha informações que não lhe sejam compreensíveis, as dúvidas podem ser sanadas com a pessoa que está lhe entrevistando e, apenas ao final, quando todos os esclarecimentos forem dados, caso concorde em participar do estudo pedimos que rubrique as folhas e assine este documento em duas vias. Uma via lhe será entregue e a outra ficará com o pesquisador responsável.

Se você não concordar em participar, isso não irá causar qualquer penalidade ou transtorno a você ou à pesquisa. Se aceitar participar, e desistir durante o andamento da pesquisa, você pode retirar o consentimento a qualquer momento, também sem nenhuma penalidade ou transtorno.

\section{INFORMAÇÕES SOBRE A PESQUISA:}

Descrição da pesquisa: esta pesquisa tem como objetivo investigar o efeito da idade na integração espectro-temporal da fala (uma habilidade auditiva). Os participantes serão submetidos à realização de exames audiológicos básicos (meatoscopia, audiometria tonal e vocal e exames imitanciométricos). Posteriormente, serão convidados a realizar um teste de reconhecimento de fala, sendo posicionados dentro de uma cabina acústica. Nesse teste, serão orientados a repetir, exatamente da forma como escutaram, sentenças em Português, que por estarem fragmentadas, irão soar de forma distorcida. O período de participação de cada participante é de aproximadamente 40 minutos.

Riscos: A pesquisa apresenta riscos mínimos que podem ser traduzidos na representação de constrangimento, e poderá ter desconforto e/ou cansaço pelo tempo que gastará. Caso isso aconteça, o voluntário deve avisar ao entrevistador, onde o mesmo imediatamente interromperá o procedimento.

Benefícios: Realização gratuita de exames audiológicos que investigam a acuidade auditiva e a integridade do sistema auditivo. Além disso, receberão a cópia dos resultados de seus exames, e caso seja identificado alguma alteração na sua audição, o pesquisador irá orientar e fazer os devidos encaminhamentos para uma avaliação mais detalhada. 
Todas as informações desta pesquisa serão confidenciais e serão divulgadas apenas em eventos ou publicações científicas, não havendo identificação dos voluntários, a não ser entre os responsáveis pelo estudo, sendo assegurado o sigilo sobre a sua participação. Os dados coletados nesta pesquisa ficarão armazenados em computador, sob a responsabilidade da pesquisadora, pelo período mínimo de 5 anos, no endereço citado anteriormente.

Nada lhe será pago e nem será cobrado para participar desta pesquisa, pois a aceitação é voluntária. Fica garantida a indenização em casos de danos, comprovadamente decorrentes da participação na pesquisa, conforme decisão judicial ou extra-judicial. Se houver necessidade, as despesas para a sua participação serão assumidas pelos pesquisadores (ressarcimento de transporte e alimentação).

Em caso de dúvidas relacionadas aos aspectos éticos deste estudo, você poderá consultar o Comitê de Ética em Pesquisa Envolvendo Seres Humanos da UFPE no endereço: (Avenida da Engenharia s/n - $1^{\circ}$ Andar, sala 4 -Cidade Universitária, Recife-PE, CEP: 50740-600, Tel.: (81)2126.8588 - e-mail: cepccs@ufpe.br).

Prof. Dra. Denise Costa Menezes

\section{CONSENTIMENTO DA PARTICIPAÇÃO DA PESSOA COMO VOLUNTÁRIO(A)}

$\mathrm{Eu}$, $\mathrm{CPF}$ , abaixo assinado, após a leitura (ou a escuta da leitura) deste documento e de ter tido a oportunidade de conversar e ter esclarecido as minhas dúvidas com o pesquisador responsável, concordo em participar do estudo "Integração espectro-temporal da fala em jovens, adultos e idosos", como voluntário(a). Fui devidamente informado(a) e esclarecido(a) pelo(a) pesquisador(a) sobre a pesquisa, os procedimentos nela envolvidos, assim como os possíveis riscos e benefícios decorrentes de 
minha participação. Foi-me garantido que posso retirar o meu consentimento a qualquer momento, sem que isto leve a qualquer penalidade.

Local e data

Assinatura do participante:

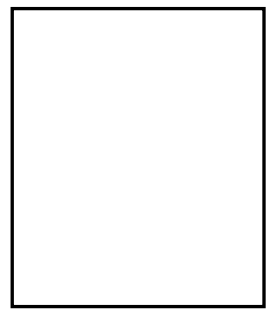

Presenciamos a solicitação de consentimento, esclarecimentos sobre a pesquisa e o aceite do voluntário em participar:

\begin{tabular}{|l|l|}
\hline Nome: & Nome: \\
\hline Assinatura & Assinatura: \\
\hline
\end{tabular}




\section{ANEXO A - LISTAS DE SENTENÇAS HINT ADAPTADO PARA O PORTUGUÊS BRASILEIRO}

\begin{tabular}{|c|c|c|}
\hline List 1 BR.tis & List 2 BR.tis & List 3 BR.tis \\
\hline $\begin{array}{l}\text { Mal dá pra assistir } \\
\text { televisão. }\end{array}$ & A mamãe está dormindo. & Tomei banho frio hoje cedo. \\
\hline Vou acordar bem cedo. & Eu ficarei com ela. & Perdi a hora outra vez. \\
\hline A torneira tá pingando. & O menino tem um amigo. & A manga está muito verde. \\
\hline Tem gente me esperando. & A menina gritou de susto. & O cachorro fugiu de casa. \\
\hline Perdi o dado do jogo. & O menino derrubou o suco. & Eu convidei muitas crianças. \\
\hline Minha irmã comprou pão. & A escada era vermelha. & Eu chamei a ambulância. \\
\hline O homem pegou o dinheiro. & Eu gosto de televisão. & O sorvete de creme está bom. \\
\hline A fábrica fechou ontem. & Não sei qual era a história. & O pássaro voou alto. \\
\hline $\begin{array}{l}\text { Meus vizinhos dormem } \\
\text { cedo. }\end{array}$ & Eu irei ao parque amanhã. & Preciso terminar a casa. \\
\hline Meu filho nasceu hoje cedo. & A pilha acabou rápido. & Eles nadarão no mar. \\
\hline Minha mãe foi para casa. & Eles ficarão no banco. & Minha amiga mora perto. \\
\hline O meu pai vendeu o sítio. & Os homens usarão calças. & Meu pai tem um sítio. \\
\hline O moço bateu o carro. & A casa terá um jardim. & Eu nadei na piscina. \\
\hline A chuva destruiu as casas. & $\begin{array}{l}\text { O motorista me esperou } \\
\text { muito. }\end{array}$ & Eu me lembrei da história. \\
\hline $\begin{array}{l}\text { Não temos lugar para } \\
\text { descanso. }\end{array}$ & O sorvete derreteu logo. & Eu não vou ao aniversário. \\
\hline $\mathrm{Na}$ feira tem frutas boas. & Ela bateu o pé na porta. & O barco afundou no rio. \\
\hline $\begin{array}{l}\text { O professor trabalhou } \\
\text { ontem. }\end{array}$ & O frango está cozido. & Os preços aumentaram muito. \\
\hline Ele não gosta de música. & Ela chamou a filha. & A casa ficará pronta. \\
\hline $\begin{array}{l}\text { A chuva derrubou o } \\
\text { telhado. }\end{array}$ & $\begin{array}{l}\text { Os bombeiros } \\
\text { conversaram. }\end{array}$ & O jornal caiu na rua. \\
\hline $\begin{array}{l}\text { É o prédio mais velho da } \\
\text { praça. }\end{array}$ & Vou tomar banho quente. & A novela será bonita. \\
\hline
\end{tabular}

\begin{tabular}{|l|l|l|}
\hline \multicolumn{1}{|c|}{ List 4 BR.tis } & \multicolumn{1}{c|}{ List 5 BR.tis } & \multicolumn{1}{c|}{ List 6 BR.tis } \\
\hline O homem parou o carro. & O menino jogou a água. & Passei meu cartão de ponto. \\
\hline Eu sempre busco pão. & Eu peguei a bicicleta. & Eu estou muito cansado. \\
\hline
\end{tabular}




\begin{tabular}{|c|c|c|}
\hline Ela não toma café com leite. & Você fez um bom trabalho. & A menina brinca de bonecas. \\
\hline $\begin{array}{l}\text { Quero doze cervejas da } \\
\text { 'brama'. }\end{array}$ & Ele se vestiu de palhaço. & É hora de dormir. \\
\hline Tá chovendo muito forte. & $\begin{array}{l}\text { Você me empurrou com } \\
\text { força. }\end{array}$ & O cachorro comerá carne \\
\hline $\begin{array}{l}\text { O meu pai comprou roupa } \\
\text { para mim. }\end{array}$ & O menino brincou na areia. & Não vi televisão hoje. \\
\hline $\begin{array}{l}\text { É meio perigoso andar } \\
\text { sozinho. }\end{array}$ & Fiquei sentado no chão. & A novela já terminou. \\
\hline $\begin{array}{l}\text { Naquela fábrica não tem } \\
\text { vaga. }\end{array}$ & Eu olhei pela janela. & O carrossel já vai rodar. \\
\hline Ela ficou com medo. & A novela terminará logo. & Vou mudar pra outra casa. \\
\hline O leite estava na mesa. & A minha letra é feia. & Quero ir embora agora. \\
\hline Visitei meus amigos. & A criança bateu a cabeça. & Eu caí de bicicleta. \\
\hline Eu ganhei um pirulito. & Tem gente gritando lá fora. & Eu estava com um amigo. \\
\hline Eu tomei banho ontem. & O almoço vai sair tarde. & Minha irmã quase chorou. \\
\hline Não vamos falar alto. & Ela não gosta de escrever. & A garrafa estava na caixa. \\
\hline Minha avó irá à praia. & Fui à festa do meu amigo. & Os tomates estavam verdes. \\
\hline A mamãe conversa com ele. & Meu pai viajou de carro. & $\begin{array}{l}\text { O cachorro brincou com o } \\
\text { osso. }\end{array}$ \\
\hline Eu brinquei em casa. & Minha mãe não ficou brava. & As tesouras estão na mesa. \\
\hline Estou cansado hoje. & O homem dirigiu bem. & $\begin{array}{l}\text { Ela perdeu seu cartão de } \\
\text { crédito. }\end{array}$ \\
\hline O menino riu da piada. & O moço se casará com ela. & A equipe jogará bem. \\
\hline Eles escutaram o barulho. & O menino quebrou o copo. & Os jovens estão dançando. \\
\hline
\end{tabular}

\begin{tabular}{|l|l|l|}
\hline \multicolumn{1}{|c|}{ List 7 BR.tis } & \multicolumn{1}{c|}{ List 8 BR.tis } & \multicolumn{1}{c|}{ List 9 BR.tis } \\
\hline Os brinquedos estão no chão. & Eu procurei meu irmão. & O meu pai jogou bola. \\
\hline A mamãe está sozinha. & Ela não chegou muito tarde. & $\begin{array}{l}\text { A gente andou na roda } \\
\text { gigante. }\end{array}$ \\
\hline Era uma bela tarde. & $\begin{array}{l}\text { Nesse fim de semana ele } \\
\text { folga. }\end{array}$ & $\begin{array}{l}\text { Meu irmão empurrou o } \\
\text { carro. }\end{array}$ \\
\hline As folhas caíam no chão. & Fui chamado pra trabalhar. & A minha tia tem um filho. \\
\hline Tenho reunião às oito. & Tem gente batendo na porta. & A menina tropeçou na pedra. \\
\hline Vou inventar uma história. & Eu não bebo no serviço. & Meu pai virá aqui hoje. \\
\hline Quero duas latas de cerveja. & A roupa no varal já secou. & O menino chorou muito. \\
\hline Quero trabalhar muito mais. & Vai ter churrasco lá em casa. & Sábado é bom para feijoada. \\
\hline Não vou comprar ovos. & Minha mulher tá grávida. & A médica tem muitas \\
\hline
\end{tabular}




\begin{tabular}{|l|l|l|}
\hline & & consultas. \\
\hline Empilhei quatro caixas. & A gente brincou na praça. & As meninas estão tristes. \\
\hline Cheguei cedo no trabalho. & O cachorro rasgou a toalha. & Eu entendi a professora. \\
\hline O avô contou uma história. & Eu irei à piscina. & Não gosto de poesias. \\
\hline O estudante dormiu aqui. & Meu pai pegou um peixe. & Eu fiz uma poesia para você. \\
\hline A mulher desmaiou na sala. & $\begin{array}{l}\text { Eu só sei escrever meu } \\
\text { nome. }\end{array}$ & Comerei logo. \\
\hline Ele precisa voltar ao país. & Eu vou ao médico depois. & $\begin{array}{l}\text { As crianças ganharam } \\
\text { brinquedos. }\end{array}$ \\
\hline A primavera é bela. & Eu comprei o presente dele. & Mamãe ligou no restaurante. \\
\hline O amor não é só sensação. & Eu venderei meu carro. & $\begin{array}{l}\text { Muito sabão mancha a } \\
\text { roupa. }\end{array}$ \\
\hline A vida é muito curta. & O uniforme já rasgou. & Os tomates acabaram cedo. \\
\hline Eles deixaram eu brincar. & A carta caiu no chão. & Não aprendi a lição. \\
\hline Eu estava escondida. & Vou viajar no fim do ano. & Meu pai pagou o aluguel. \\
\hline
\end{tabular}

\begin{tabular}{|c|c|c|}
\hline List 10 BR.tis & List 11 BR.tis & List 12 BR.tis \\
\hline Ainda não tomei meu café. & Ela tinha muitos presentes. & Ele caiu da árvore. \\
\hline Ele rasgou a camisa nova. & Quero comer ovo frito. & A cachorrinha não é brava. \\
\hline O estacionamento é longe. & O torcedor gritou no jogo. & $\begin{array}{l}\text { Vou comprar um rádio na } \\
\text { loja. }\end{array}$ \\
\hline Perdi os meus documentos. & A criança tomou chuva. & O pastelzinho da feira é jóia. \\
\hline O bebê só chora à noite. & Ele comeu peixe assado. & Preciso fazer a barba. \\
\hline O ladrão levou o dinheiro. & A menina canta bonito. & No fim de semana tem jogo. \\
\hline Vai lá em casa tomar sol. & O aluno acertou a questão. & Vai ter churrasco domingo. \\
\hline Vamos chegar bem cedo. & Os cavalos fugiram hoje. & $\begin{array}{l}\text { Hoje eu tô morrendo de } \\
\text { fome. }\end{array}$ \\
\hline Eu tô feliz aqui no alto. & Esse refrigerante tá quente. & Você ganhou um jogo. \\
\hline $\begin{array}{l}\text { Já começou a trabalhar de } \\
\text { carro. }\end{array}$ & Só bebi duas cervejas. & $\begin{array}{l}\text { A senhora fez café para } \\
\text { você. }\end{array}$ \\
\hline Gosto de conversar na rua. & O churrasco acabou logo. & Tô muito atrasado hoje. \\
\hline $\begin{array}{l}\text { A menina ganhou uma } \\
\text { boneca. }\end{array}$ & A loja vendeu com desconto. & Sua blusa está na cadeira. \\
\hline O empregado limpa o chão. & O menino pedia socorro. & O jogador fez muita falta. \\
\hline
\end{tabular}




\begin{tabular}{|l|l|l|}
\hline Ela cortará a carne. & $\begin{array}{l}\text { Ela desfila com roupas da } \\
\text { moda. }\end{array}$ & Andei até o ponto de ônibus. \\
\hline A comida está cara. & Meu marido chega tarde. & Não pude trabalhar hoje. \\
\hline Preciso falar com você. & A estudante mora longe. & Eu brinquei com ele. \\
\hline Eu também desenhei bem. & A torcida verá o jogo. & Brinquei na minha avó. \\
\hline Ele perdeu o boné ontem. & O motorista bateu o carro. & As crianças estão perdidas. \\
\hline Ele tava com pressa pra sair. & Ele pagou sua conta em dia. & $\begin{array}{l}\text { A professora tem roupa } \\
\text { chique. }\end{array}$ \\
\hline Já vou pagar o aluguel. & Eles queriam batatas. & Uma casa foi construída. \\
\hline
\end{tabular}


ANEXO B - PARECER CONSUBSTANCIADO DO CEP

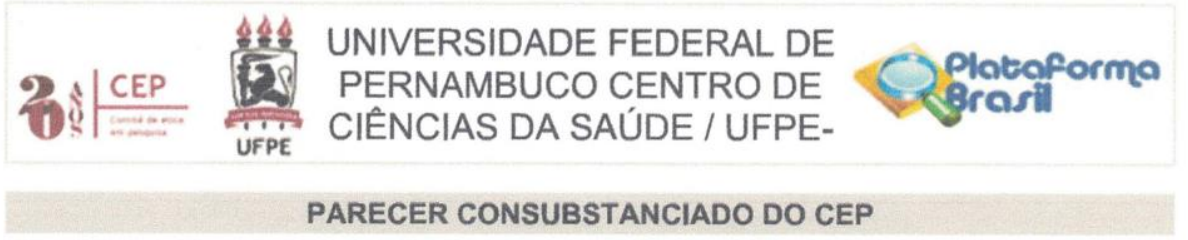

DADOS DO PROJETO DE PESQUISA

Título da Pesquisa: Integração espectro-temporal da fala em jovens, adultos e idosos.

Pesquisador: DENISE COSTA MENEZES

Área Temática:

Versão: 1

CAAE: 81081417.1 .0000 .5208

Instituição Proponente: Universidade Federal de Pernambuco - UFPE

Patrocinador Principal: Financiamento Próprio

DADOS DO PARECER

Número do Parecer: 2.532 .384

Apresentação do Projeto:

O projeto intitulado "INTEGRAÇÃO ESPECTRO-TEMPORAL DA FALA EM JOVENS, ADULTOS E IDOSOS" será desenvolvido pela professora DENISE COSTA MENEZES, do Programa de pós-graduação e Saúde da Comunicaçăo Humana. A pesquisa será desenvolvida com a participação de 36 pessoas com idade a partir de 18 anos, de ambos os sexos. A amostra será dividida em três grupos: Grupo de Jovens: 12 indivíduos, com idade entre 18 e 25 anos; Grupo de adultos de Meia Idade: 12 indivíduos, com idade entre 45 e 55 anos; Grupo de Idosos: 12 indivíduos, a partir de 60 anos. Serăo convidados a participar do estudo e em data agendada, de acordo com a conveniência do participante. Após a assinatura do TCLE, serăo submetidos a exames audiológicos: meatoscopia e audiometria tonal. Posteriormente serão realizados os testes com a fala fragmentada (segmentado em tempo e em espectro de frequência, separadamente e simultaneamente). Para a realização dos testes de fala, o participante se posicionará sentado dentro de uma cabina acústica e receberá, através de fone auditivo, o estímulo de fala segmentada de acordo com cada protocolo. Será escolhida para o teste a orelha de melhor audiçăo ou a orelha direita, quando ambas apresentarem acuidade auditiva semelhante. Os participantes serão instruídos a repetir as sentenças como ouvirem, mesmo que nem todas as palavras sejam inteligíveis.

Objetivo da Pesquisa:

OBJETIVOS

Geral: Investigar a habilidade de integraçăo espectro-temporal da fala em jovens, adultos e idosos.

Endereço: Av, da Engenharia $s / n^{\circ}-1^{\circ}$ andar, sala 4, Prédio do Centro de Ciências da Saúde

Bairro: Cidade Universitária CEP: $50.740-600$

UF: PE Municipio: RECIFE

Telefone: (81)2126-8588

E-mail: cepccs@ufpe.br 
6 (1) CIFP

Continuaçáso do Parecer: 2.532.384

Especificos:

a) Determinar, em funçăo da idade, a habilidade de integraçăo da fala segmentada em espectro de frequência;

b) Determinar, em função da idade, a habilidade de integração da fala segmentada em tempo;

c) Determinar, em função da idade, a habilidade de integração da fala segmentada, simultaneamente, em espectro de frequência e em tempo.

\section{Avaliação dos Riscos e Benefícios:}

A pesquisadora apresenta ponderação entre riscos e benefícios. Como riscos, considera que podem ser traduzidos em constrangimento, e poderá ter desconforto e/ou cansaço pelo tempo que gastará no exame. Caso isso aconteça, o pesquisador imediatamente interromperá o procedimento.

Quanto aos benefícios, o participante realizará exames audiológicos gratuitamente, importantes para a avaliaçăo da integridade do sistema auditivo. Além disso, receberăo a cópia dos resultados de seus exames, e caso seja identificado alguma alteração na sua audição, o pesquisador irá orientar e fazer os devidos encaminhamentos para uma avaliação mais detalhada.

Comentários e Considerações sobre a Pesquisa:

Como justificativa do estudo a pesquisadora argumenta que o sistema auditivo de jovens vem sendo amplamente estudada como referência comparativa com a audição de idosos. Por outro lado, estudos da audição de adultos em idade intermediária ainda não são abundantes na literatura. O presente estudo pretende contribuir para o aumento das informações sobre as dificuldades auditivas em ambientes sociais permeados por ruídos mascarantes (através da investigaçăo da habilidade em integrar os fragmentos da fala) em populaçōes de três faixas etárias: jovens, adultos e idosos.

Considerações sobre os Termos de apresentação obrigatória:

Os pesquisadores apresentaram os seguintes termos e/ou documentos exigidos pela Resolução 466/12:

- Carta de anuência da Chefia do departamento de Fonoaudiologia.

- Folha de rosto assinada pela Chefe do departamento de Fonoaudiologia.

- Termo de compromisso e confidencialidade do pesquisador responsável.

Endereço: Av. da Engenharia s/ $/ n^{\circ}-1^{\circ}$ andar, sala 4, Prédio do Centro de Ciências da Saúde Bairro: Cidade Universitária $\quad$ CEP: $50.740-600$

UF: PE Municipio: RECIFE

Telefone: (81)2126-8588

E-mail: cepccs@ufpe.br 
$6)$ C.

Continuaçå do Parecer: 2.532.384

\section{Recomendações:}

Sem recomendaçöes.

Conclusões ou Pendências e Lista de Inadequações:

Aprovado.

Considerações Finais a critério do CEP:

O Protocolo foi avaliado na reuniăo do CEP e está APROVADO para iniciar a coleta de dados. Informamos que a APROVAÇÃO DEFINITIVA do projeto só será dada após o envio da Notificação com o Relatório Final da pesquisa. O pesquisador deverá fazer o download do modelo de Relatório Final para enviá-lo via "Notificação", pela Plataforma Brasil. Siga as instruções do link "Para enviar Relatório Final", disponível no site do CEP/UFPE. Após apreciação desse relatório, o CEP emitirá novo Parecer Consubstanciado definitivo pelo sistema Plataforma Brasil.

Informamos, ainda, que o (a) pesquisador (a) deve desenvolver a pesquisa conforme delineada neste protocolo aprovado, exceto quando perceber risco ou dano não previsto ao voluntário participante (item V.3., da Resolução CNS/MS N 466/12).

Eventuais modificações nesta pesquisa devem ser solicitadas através de EMENDA ao projeto, identificando a parte do protocolo a ser modificada e suas justificativas.

Para projetos com mais de um ano de execuçăo, é obrigatório que o pesquisador responsável pelo Protocolo de Pesquisa apresente a este Comitê de Ética, relatórios parciais das atividades desenvolvidas no período de 12 meses a contar da data de sua aprovaçăo (item X.1.3.b., da Resoluçăo CNS/MS N 466/12). O CEP/UFPE deve ser informado de todos os efeitos adversos ou fatos relevantes que alterem o curso normal do estudo (item V.5., da Resolução CNS/MS N ${ }^{\circ} 466 / 12$ ). É papel do/a pesquisador/a assegurar todas as medidas imediatas e adequadas frente a evento adverso grave ocorrido (mesmo que tenha sido em outro centro) e ainda, enviar notificação à ANVISA - Agência Nacional de Vigilância Sanitária, junto com seu posicionamento.

Este parecer foi elaborado baseado nos documentos abaixo relacionados:

\begin{tabular}{|c|c|c|c|c|}
\hline Tipo Documento & Arquivo & Postagem & Autor & Situaçăo \\
\hline $\begin{array}{l}\text { Informaçōes Básicas } \\
\text { do Projeto }\end{array}$ & $\begin{array}{l}\text { PB_INFORMAÇOES_BASICAS_DO_P } \\
\text { ROJETO 923763.pdf }\end{array}$ & $\begin{array}{c}13 / 12 / 2017 \\
12: 24: 09\end{array}$ & & Aceito \\
\hline $\begin{array}{l}\text { Projeto Detalhado / } \\
\text { Brochura }\end{array}$ & PROJETOFINALIZADO13DEZ.docX & $\begin{array}{c}13 / 12 / 2017 \\
12: 23: 41\end{array}$ & $\begin{array}{l}\text { DENISE COSTA } \\
\text { MENEZES }\end{array}$ & Aceito \\
\hline
\end{tabular}

Endereço: Av. da Engenharia $s / n^{\circ}-1^{\circ}$ andar, sala 4, Prédio do Centro de Ciências da Saúde Bairro: Cidade Universitária CEP: $50.740-600$

UF: PE Municipio: RECIFE

Telefone: (81)2126-8588

E-mail: cepccs@ufpe.br 


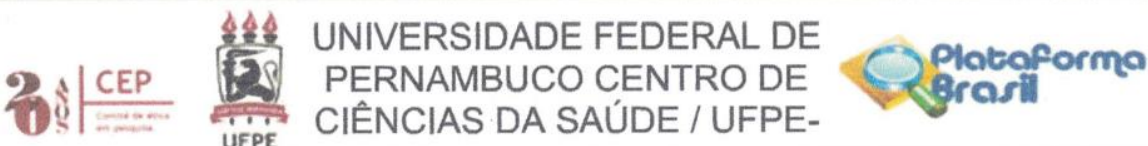

Continuaçso do Parecer. 2.532.384

\begin{tabular}{|c|c|c|c|c|}
\hline Investigador & PROJETOFINALIZADO13DEZ,docX & $\begin{array}{c}13 / 12 / 2017 \\
12: 23: 41\end{array}$ & $\begin{array}{l}\text { DENISE COSTA } \\
\text { MENEZES } \\
\end{array}$ & Aceito \\
\hline $\begin{array}{l}\text { TCLE / Termos de } \\
\text { Assentimento / } \\
\text { Justificativa de } \\
\text { Ausência } \\
\end{array}$ & TCLENOVO13dez.docx & $\begin{array}{l}13 / 12 / 2017 \\
12: 22: 13\end{array}$ & $\begin{array}{l}\text { DENISE COSTA } \\
\text { MENEZES }\end{array}$ & Aceito \\
\hline Outros & $\begin{array}{l}\text { TERMODECOMPROMISSOECONFIDE } \\
\text { NCIALIDADE.pdf } \\
\end{array}$ & $\begin{array}{c}05 / 09 / 2017 \\
11: 45: 04\end{array}$ & $\begin{array}{l}\text { DENISE COSTA } \\
\text { MENEZES } \\
\end{array}$ & Aceito \\
\hline $\begin{array}{l}\text { Declaração de } \\
\text { Instituição e } \\
\text { Infraestrutura } \\
\end{array}$ & CARTADEANUENCIADENISE.pdf & $\begin{array}{l}05 / 09 / 2017 \\
10: 57: 20\end{array}$ & $\begin{array}{l}\text { DENISE COSTA } \\
\text { MENEZES }\end{array}$ & Aceito \\
\hline Outros & CVSILVANA.pdf & $\begin{array}{c}08 / 06 / 2017 \\
16: 53: 25\end{array}$ & $\begin{array}{l}\text { DENISE COSTA } \\
\text { MENEZES }\end{array}$ & Aceito \\
\hline Outros & CVFERNANDO.pdf & $\begin{array}{c}08 / 06 / 2017 \\
16: 53: 05\end{array}$ & $\begin{array}{l}\text { DENISE COSTA } \\
\text { MENEZES }\end{array}$ & Aceito \\
\hline Outros & CVKARINA.pdf & $\begin{array}{l}08 / 06 / 2017 \\
16: 40: 55\end{array}$ & $\begin{array}{l}\text { DENISE COSTA } \\
\text { MENEZES }\end{array}$ & Aceito \\
\hline Outros & CLRAYANE.pdf & $\begin{array}{c}08 / 06 / 2017 \\
16: 23: 40\end{array}$ & $\begin{array}{l}\text { DENISE COSTA } \\
\text { MENEZES }\end{array}$ & Aceito \\
\hline Folha de Rosto & FOLHADEROSTOASSINADA.pdf & $\begin{array}{c}08 / 06 / 2017 \\
16: 22: 13 \\
\end{array}$ & $\begin{array}{l}\text { DENISE COSTA } \\
\text { MENEZES } \\
\end{array}$ & Aceito \\
\hline Outros & CVANGLEINA.pdf & $\begin{array}{c}18 / 05 / 2017 \\
19: 43: 17 \\
\end{array}$ & $\begin{array}{l}\text { DENISE COSTA } \\
\text { MENEZES } \\
\end{array}$ & Aceito \\
\hline Outros & CVDENISE.pdf & $\begin{array}{c}18 / 05 / 2017 \\
19: 42: 50\end{array}$ & $\begin{array}{l}\text { DENISE COSTA } \\
\text { MENEZES }\end{array}$ & Aceito \\
\hline
\end{tabular}

Situação do Parecer:

Aprovado

Necessita Apreciação da CONEP:

Não

RECIFE, 08 de Março de 2018

Assinado por:

Gisele Cristina Sena da Silva Pinho

(Coordenador)

Endereço: Av, da Engenharia $s / n^{\circ}-1^{\circ}$ andar, sala 4, Prédio do Centro de Ciências da Saúde

Bairro: Cidade Universitária

CEP: $50.740-600$

UF: PE

Município: RECIFE

Telefone: (81)2126-8588

E-mail: cepccs@ufpe.br 